\title{
Structure, Materials and Processes in the Earth's Core and Mantle
}

\author{
Véronique Dehant ${ }^{1,2}$ (D) Saioa A. Campuzano ${ }^{3} \cdot$ Angelo De Santis $^{4}$. \\ Wim van Westrenen ${ }^{5}$ (D)
}

Received: 10 May 2021 / Accepted: 1 December 2021 / Published online: 1 February 2022

(c) The Author(s) 2022

\begin{abstract}
This paper reviews current knowledge about the Earth's core and the overlying deep manthe in terms of structure, chemical and mineralogical compositions, physical properties, and dynamics, using information from seismology, geophysics, and geochemistry. Highpressure experimental techniques that can help to interpret and understand observations of these properties and compositions in the deep interior are summarized. The paper also examines the consequences of core flows on global observations such as variations in Earth's rotation and orientation or variations in the Earth's magnetic field. Processes currently active at the core-mantle boundary and the various coupling mechanisms between the core and the mantle are discussed, together with some evidence from magnetic field observations.
\end{abstract}

Keywords Earth's core · Earth's rotation · Interior structure · Earth's magnetic field

\section{Article Highlights}

- Current knowledge about the deep mantle in terms of structure, chemical, and mineralogical compositions, and dynamics encompasses particular structures in the mantle, such as large low shear-wave velocity provinces (LLSVPs) under the Pacific Ocean and under the southwestern part of Africa and bordering parts of the Atlantic and Indian Ocean, with inferred lateral flow regime in the D"-zone where seismic velocity gradients are anomalously low. Subduction has mostly been confined to this belt with a net divergence and convergence of the plates and two divergence poles at approximately

Véronique Dehant

v.dehant@oma.be

$\triangle$ Wim van Westrenen

w.van.westrenen@vu.nl

1 Royal Observatory of Belgium, 1180 Uccle, Belgium

2 Université Catholique de Louvain (UCLouvain), 1348 Ottignies-Louvain-la-Neuve, Belgium

3 IGEO, 28040 Madrid, Spain

4 Istituto Nazionale di Geofisica e Vulcanologia, 00143 Rome, Italy

5 Vrije Universiteit Amsterdam, 1081 HV Amsterdam, The Netherlands 
$180^{\circ}$ located above the LLSVPs. The global pattern, including upwelling material underneath mid-ocean ridges, suggests a large-scale degree- 2 convection

- In addition to being flattened, the Core-Mantle Boundary (CMB) is bumpy due to the subducting slabs sinking down to that boundary. The core and the mantle are coupled due to mechanisms applied at the CMB such as electromagnetic, viscous or topographic coupling

- High-pressure and high-temperature experimental techniques can help to interpret the observations and understand the deep interior

- Some evidence obtained from magnetic field observations can also shed light on processes operating there; the magnetic field observed at and above the Earth's surface has to extended down to the CMB. The current decay of the dipole moment and the presence of the South Atlantic Anomaly (SAA) at the CMB may indicate a possible upcoming geomagnetic transition, such as an excursion or a reversal. The occurrence of geomagnetic jerks, abrupt and sharp changes in the secular variation of the geomagnetic field, is related to motion in the core such as the arrival of localized Alfven waves

\section{Introduction}

In the overall framework of understanding the deep interior of the Earth in order to explain observations such as the gravity field, nutations (time variations of the Earth's orientation in space), length-of-day variations or magnetic field variations, it is important to start from what we know in terms of structure, composition, and dynamics. Recent developments in geodynamics as well as in the quality of these observations are discussed throughout this volume. Here we concentrate on what we know about the deep interior of our planet, focusing mostly on the metallic core and overlying deepest parts of the mantle.

Below the outermost solid layer, one finds the visco-elastic mantle extending from the base of the crust down to an average depth of $2891.5 \mathrm{~km}$ (AK135 model, Kennett et al. 1995). Further below lies the fluid outer core, central to this book, and finally, the solid inner core of mean radius of $1217.5 \mathrm{~km}$ (AK135 model, Kennett et al. 1995). In constructing general models for the structure and properties of the interior of the Earth today (density, elastic properties, etc., as a function of position), changes induced by geologically fast time-dependent processes of all kinds are usually disregarded, except if they have consequences for very long-term dynamics. This is also the case for the complex motions in the fluid outer core. The coupling mechanisms at the liquid core-mantle boundary (CMB) are, nevertheless, important to be studied in order to better understand the deep Earth's interior, as well as to assess their influence on the gravity field, the magnetic field and on the Earth's rotation. Precise knowledge of the rotation of the Earth, as well as of the magnetic and gravity fields, has numerous societal applications. For example, precise positioning determined using geodetic techniques such as the Global Navigation Satellite System (GNSS) is based on two reference frames: the terrestrial frame, fixed relative to the Earth and rotating synchronously with the planet, and the celestial frame, fixed in space, in which the orbits of artificial satellites are described. The relationship between these reference frames strongly depends on the Earth's rotation that is subject to important irregularities caused by numerous processes (in particular from the Earth's core) acting on a broad range of time scales. As the second example, advanced understanding of space weather of all intensities and of its implications for society requires understanding of the core field processes. 
The study of the Earth's interior is hampered by a lack of direct observations. One exception is observations from seismology, providing information on the physical state, density structure, and elastic properties of the different layers of the Earth, through travel time, amplitude, and phase measurements of seismic waves. Other key aspects such as flow in the liquid core are very hard to study using seismology. Flow in the liquid core can be derived from other indirect observations that provide constraints on theoretical models, so that the dynamics of the liquid core is deduced from the observed consequences of these flows. The structure of the lowermost mantle and the properties of the CMB are important for core fluid dynamics, and this is the reason why we address these subjects here. Highpressure experimental techniques that can help to interpret and understand direct and indirect observations of the properties of Earth's deep interior are also summarized.

We do not pretend to provide a complete review of the Earth's structure but we will discuss the most important properties for core dynamics in view of the topics covered in the remainder of this volume. This article is organized as follows: important mantle composition, structure and dynamical models that attempt to explain what is deduced from seismic observations will be described in Sect. 2. We do not provide an exhaustive list of possibilities of modeling the mantle, but rather consider models important for the outer core dynamics and we address in particular the large low S-wave velocity provinces (LLSVPs, see Sect. 2.3) and the ultra-low velocity zones (ULVZs, see Sect. 2.4) near the CMB. Various compositional models of the mantle predict very subtle differences in physical properties such as density and seismic wave velocity (e.g., Jackson 1983, 1998). Accurate constraints on chemical composition are therefore very hard to obtain from geophysical approaches. Laboratory high-pressure/high-temperature experiments help constrain observations as reviewed in Sects. 2 and 5. The core composition, structure and dynamics are addressed in Sect. 3 and what is happening at the CMB, in Sect. 4. The observations that are used for these descriptions are of course coming mainly from seismology, but geodesy (addressed in Sect. 4.3) can be used to further infer interior properties, at the CMB in particular. The main results from laboratory experiments for constraining core or mantle properties are used throughout the paper, and the techniques used to do this are summarized in Sect. 5. The magnetic field and what we can deduce about the core are addressed in Sect. 6. An overview of future research directions is addressed in the last section.

\section{Mantle Composition, Structure and Dynamics}

Many current models of early Earth evolution invoke a stage in which both the mantle and the core of the Earth were completely molten in the aftermath of the giant impact that formed the Moon. At the time of the giant impact, most of the Earth's core had already formed by equilibrating molten metal and molten silicate within the accreting planetesimals and planetary embryos, as well as at the base of a terrestrial magma ocean, estimated to be 40-60 GPa deep, followed by segregation of the metal through the solid lower mantle (e.g., Wood et al. 2006). Whole-Earth melting after core formation might cause extensive chemical exchange between the core and the adjacent magma ocean (MO). Due to the relation between the likely temperature distribution in the molten mantle and the liquidus curve of mantle rock, the mantle is thought to have crystallized upward and downward from the middle. The earliest crystallization at a neutral buoyancy level separated the mantle into an upper MO, a middle crystalline shell and a basal magma ocean (BMO). The 
upper MO crystallized rapidly upwards from the bottom due to efficient heat loss to the surface, whereas the BMO became thermally insulated and crystallized slowly. Chemical $\mathrm{BMO}$-core exchange continued during protracted BMO solidification. After this stage, the continuous input of recycled oceanic crust (ROC) and lithosphere into the Earth's mantle started with deep subduction at about $3 \mathrm{Ga}$. The $\mathrm{D}^{\prime \prime}$ layer, identified by seismology, and occupying the lowermost $200-340 \mathrm{~km}$ of the present-day lower mantle (at a depth of $\sim 2891.5 \mathrm{~km}$ ) is a layer that is compositionally different to the other parts of the lower mantle and related to this ROC.

Since then, a volume roughly estimated to be equivalent to 2.5 times the total mantle volume might have (re-)entered the mantle. Seismically observable 5-40 km thick and variable ultra-low velocity zones (ULVZs), just above the core-mantle boundary, may represent partially leaky "windows" between the present-day core and mantle. The ULVZs are thickest in the root zones of deep plumes.

Table 1 Terminology of mantle minerals and rocks

\begin{tabular}{ll}
\hline Name & Explanation \\
\hline Basalt & $\begin{array}{c}\text { Basaltic magmas are formed by partial melting of peridotite at low pressure (near the } \\
\text { Earth's surface). The oceanic crust has basaltic composition }\end{array}$ \\
Bridgmanite & $\begin{array}{c}\text { Bridgmanite is the Earth's most abundant mineral and has } \mathrm{MgSiO}_{3} \text { as the main component. } \\
\text { With lesser amounts of the other components } \mathrm{Fe} \mathrm{AlO}_{3}, \mathrm{FeSiO}_{3} \text { and } \mathrm{Al}_{2} \mathrm{O}_{3} \text {, the simplest } \\
\\
\text { general formula can be expressed as (Mg,Fe)(Al,Si) } \mathrm{O}_{3}\end{array}$ \\
Eclogite & $\begin{array}{c}\text { Eclogite is a moderate- to high-pressure form of basalt, stable at pressures of about 1-14 } \\
\mathrm{GPa}\end{array}$
\end{tabular}

Ferropericlase Ferropericlase or magnesiowüstite is a solid solution between magnesium and iron oxide with the chemical formula $(\mathrm{Mg}, \mathrm{Fe}) \mathrm{O}$

Garnet Garnet has general formula $\mathrm{X}_{3} \mathrm{Y}_{2}\left(\mathrm{SiO}_{4}\right)_{3}$, where $\mathrm{X}$ is divalent cations $(\mathrm{Ca}, \mathrm{Mg}, \mathrm{Fe}, \mathrm{Mn})^{2+}$ and $\mathrm{Y}$ is trivalent cations $(\mathrm{Al}, \mathrm{Fe}, \mathrm{Cr})^{3+}$. In the deepest part of the upper mantle, through the transition zone and into the shallow part of the lower mantle, the garnet mineral assimilates pyroxenes to form an additional "majoritic" component with the simplest formula $\mathrm{Mg}_{3} \mathrm{Al}_{2}\left(\mathrm{SiO}_{4}\right)_{3}$

Garnetite Garnetite is also a high-pressure form of basalt, dominated by garnet, and stable in the 14-30 GPa pressure range

Harzburgitic Harzburgite is an ultramafic rock, a variety of peridotite consisting mostly of olivine and low-calcium $(\mathrm{Ca})$ pyroxene

Kimberlites Kimberlite is an igneous/magmatic rock formed at depth from anomalously enriched exotic mantle compositions and erupted rapidly and violently

Olivine Olivine formula $(\mathrm{Mg}, \mathrm{Fe})_{2} \mathrm{SiO}_{4}$

Peridotite Peridotite is the dominant mantle rock in terrestrial (Earth-like) planets, containing mainly olivine and pyroxene at low pressure and bridgmanite (about $75 \%$ ), ferropericlase $(20 \%)$ and Ca-perovskite (5\%) at the conditions of the Earth's lower mantle

Pyroxene Pyroxene general formula $\mathrm{XY}(\mathrm{Si}, \mathrm{Al})_{2} \mathrm{O}_{6}$, where $\mathrm{X}$ is typically a mixture dominated by calcium, sodium, iron(II) or magnesium, and Y represents ions of smaller size, including mainly chromium, aluminum, iron(III), and magnesium

Ringwoodite Ringwoodite, a third $(\mathrm{Mg}, \mathrm{Fe})_{2} \mathrm{SiO}_{4}$ polymorph, is stable at higher pressures than wadsleyite. Olivine, wadsleyite and ringwoodite were previously referred to as the $\alpha, \beta$ (modified spinel) and $\gamma$ (spinel) phases, respectively

Seifertite Seifertite is one of the densest polymorphs of silica, a silicate mineral with the formula $\mathrm{SiO}_{2}$

Silica Silica or silicon dioxide has the chemical formula $\mathrm{SiO}_{2}$

Wadsleyite Wadsleyite is a high-pressure polymorph of olivine, $(\mathrm{Mg}, \mathrm{Fe})_{2} \mathrm{SiO}_{4}$, with the same general formula 
Additionally, with a CMB temperature of $4000 \mathrm{~K}$, temperature gradients of 5-10 K/ $\mathrm{km}$ through the thermochemical boundary layer of the D"-zone, which are very steep compared to the various mantle adiabats (plume adiabats to cold subducted slab adiabats) of about $0.3 \mathrm{~K} / \mathrm{km}$, will also variably affect the densities of the different lithologies.

The rocks that are appearing in our discussion in the following sub-sections are presented in Table 1.

\subsection{Mantle Composition}

The bulk composition of the current mantle is commonly represented by pyrolitic models (term derived from the mineral names PYR-oxene and OL-ivine) based on the complementary relationship between melt-depleted peridotite and basalt identified in the 1960s (Ringwood 1962a, b; Green and Ringwood 1963). Subsequently, McDonough and Sun (1995) constructed more sophisticated compositional models of broadly "pyrolitic" compositions for the primitive mantle or bulk silicate Earth (BSE) by evaluating the chemical composition of numerous upper mantle (UM) peridotites to identify the least melt-depleted samples, before adding an appropriate amount of a suitable partial melt. An important question is whether the bulk silicate mantle or BSE is also pyrolitic. Alternatively, the BSE may tend toward a chondritic composition, characterized by an elevated $\mathrm{Si} /(\mathrm{Mg}+\mathrm{Fe})$ ratio and therefore elevated pyroxene/olivine and bridgmanite/ferropericlase ratios in the upper mantle (UM) and lower mantle (LM), respectively. Several geochemical, mineral physical, seismic, and geodynamic studies have concluded that the LM might have an elevated $\mathrm{Si} /(\mathrm{Mg}+\mathrm{Fe})$ ratio compared to the $\mathrm{UM}$ and transition zone (TZ), containing domains enriched in bridgmanite (e.g., Murakami et al. 2012; Ballmer et al. 2017; Trønnes et al. 2019; Mashino et al. 2020). For instance, Murakami et al. (2012) mention that the mineralogical model that provides the best fit to a global seismic velocity profile favors a LM with perovskite for more than 93 percent, which is a much higher proportion than that predicted by the conventional homogeneous peridotitic mantle model.

\subsection{Mantle Structure, Mineralogy and Lithological Density Relations}

The dominantly peridotitic mantle is divided into the UM, TZ, and LM by seismic discontinuities at 410 and $660 \mathrm{~km}$ depth, caused by the phase transitions from olivine to wadsleyite and from ringwoodite to bridgmanite + ferropericlase, respectively (e.g., Stixrude and Lithgow-Bertelloni 2011, 2012; Irifune and Tsuchiya 2015). Less distinct phase transitions at 520-540 km depth may result from the wadsleyite to ringwoodite transition and the stabilization of the minor Ca-perovskite phase (Deuss and Woodhouse 2001; Saikia et al. 2008). The important TZ mineral, garnet, remains stable in the uppermost part of LM, but dissolves gradually into bridgmanite with increasing pressure in the $660 \mathrm{~km}$ to about $800 \mathrm{~km}$ depth range, causing a steep seismic velocity gradient in that range. Stixrude and Lithgow-Bertelloni $(2011,2012)$ and Irifune and Tsuchiya (2015) review the radial variation in average shear-wave velocity $\left(V_{\mathrm{S}}\right)$ and the mineral proportions for various lithological compositions (depleted peridotite, fertile or pyrolitic peridotite and basalt) throughout the mantle down to the CMB at $2891 \mathrm{~km}$ depth.

Seismic tomography, a technique for imaging the subsurface of the Earth with seismic waves, shows large lateral velocity variations in the UM, with slow regions under the 

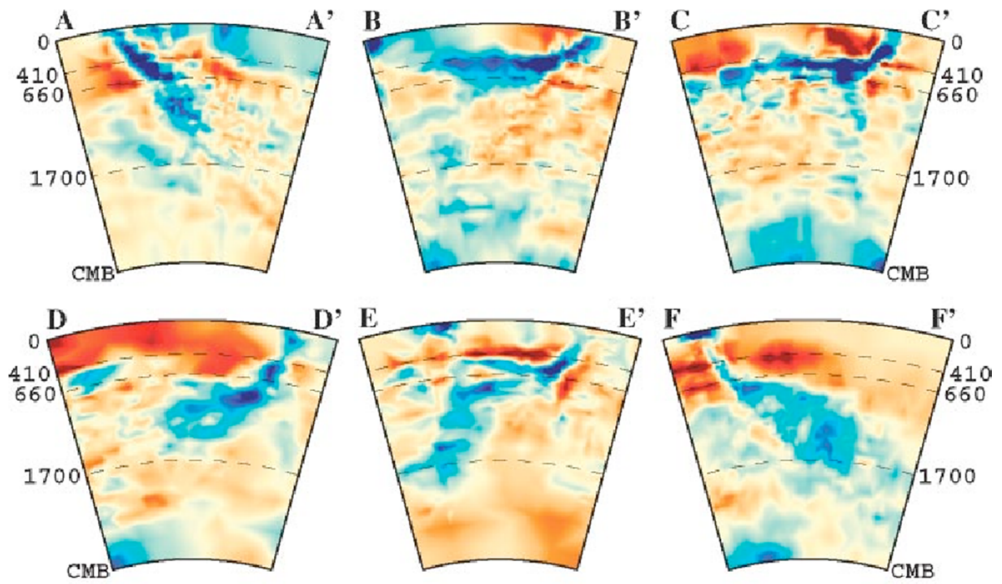

$(-0.9 \%)$ slow

fast $(+0.9 \%)$

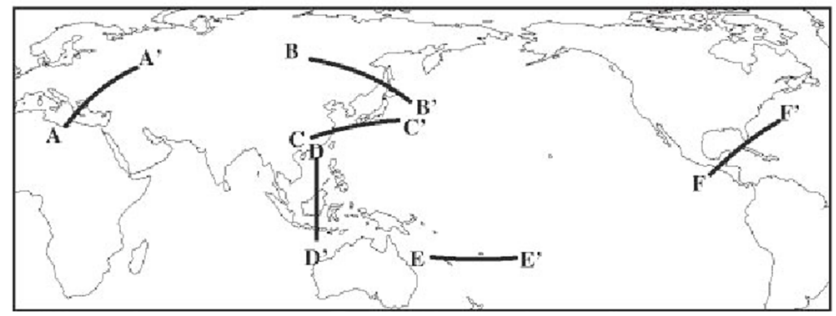

Fig. 1 Examples of depth cross sections in several subduction zone areas showing fast anomalies associated with subducted slabs from Romanowicz (2003)

mid-ocean ridges and subduction zones and fast regions under Archean cratons, suggesting heterogeneities in temperature and/or composition. For the five different S-wave tomography models shown by Romanowicz (2003, see Fig. 1 reproduced here from that paper) and Lay (2015), the root-mean-square (RMS) amplitudes for shear-wave velocities of 2.3-2.8\% in the 50-200 km depth range (reflecting the presence of these heterogeneities) decrease markedly to a level of $0.3-0.6 \%$ in the $700-2500 \mathrm{~km}$ depth range. This reflects a reduced degree of compositional/thermal heterogeneity. Below this almost featureless region in the LM, the RMS amplitudes for shear-wave velocities increase to values of $0.8-1.6 \%$ in the lowermost $300-400 \mathrm{~km}$ of the mantle. In contrast, the RMS maxima of $0.30-1.36 \%$ at $50 \mathrm{~km}$ depth for the four P-wave models in Lay (2015) decrease to $0.25-0.34 \%$ at $660 \mathrm{~km}$ depth and slightly further to $0.15-0.29 \%$ in the $900-2891 \mathrm{~km}$ depth range. It is important to note the absence of any significant increase in the amplitude of the P-wave velocity variation in the lowermost mantle and that the strongly increasing amplitudes in the S-wave velocity variations are restricted to the lowermost $300-400 \mathrm{~km}$ of the mantle. This region, referred to as the D" zone, coincides with the thermal boundary layer above the CMB, where temperatures increase strongly from an average mantle adiabat of about $2500 \mathrm{~K}$ at $2600 \mathrm{~km}$ depth (e.g., Stixrude et al. 2009) to a CMB temperature of about $4000 \mathrm{~K}$. As described in Sects. 2.3 and 2.4, the D" zone with its distinct compositional domains 
combined with strong lateral gradients and contrasts in temperature, density and viscosity, are fundamentally important for deep Earth evolution and dynamics.

Variations in seismic velocities can be attributed to many processes going from relative temperature variations, lattice preferred orientation, partial melting, compositional changes, volatile content to the contamination of the inversion itself. At the end of the data inversion procedure, one obtains a seismic velocity model that best fits the data with a certain estimation of the uncertainty, which is at the level of a couple of tenths of percent. Sometimes, formal covariances of the inversion are provided. Sometimes, synthetic data are generated to verify the accuracy of the estimations (e.g., Leveque et al. 1993). Sometimes, one finds quantification of the relative variance of traveltimes from different data subsets (e.g., Gibbons et al. 2020). However, there are multiple complicated aspects related to damping and smoothing, which can artificially broaden or smear structures to be retrieved, to contamination from the background model, non-uniqueness of the inversion, uneven data coverage, and choices in model parametrization (e.g., Burdick and Lekić 2017). In case of interpretation using laboratory experiments, there is also an influence of the averaging scheme when estimating the velocity of a mixture. In that case, there is a method based on the Voigt-Reuss-Hill average, which provides a simple way to estimate the properties of a textured polycrystal (Man and Huang 2011).

\subsection{Large Low S-Wave Velocity Provinces (LLSVPs) and Degree-2 Convection Pattern}

The strong lateral $V_{\mathrm{S}}$ variation in the $\mathrm{D}$ "-zone defines two antipodal so-called large low shear-wave velocity provinces (LLSVPs): one under the Pacific Ocean and the other under the southwestern part of Africa and bordering parts of the Atlantic and Indian Ocean. These two provinces are separated by a high-velocity longitudinal belt centered relatively close to the $120 \mathrm{E}$ and $70 \mathrm{~W}$ meridians, crossing Asia, Australia, Antarctica, the Americas and the Arctic (e.g., Becker and Boschi 2002).

The Earth's residual geoid (Hager et al. 1985; Hager and Richards 1989; Steinberger and Torsvik 2008, 2010; Burke and Torsvik 2012) and free-air gravity (Ishii and Tromp 1999) reveal a degree- 2 mantle convection pattern with antipodal broad outflow columns above the two LLSVPs, combined with the wide longitudinal belt of sheet-like inflow (downwelling). Although plate tectonic reconstructions are uncertain prior to the Pangea assembly, it appears that subduction during the past 540 Ma has mostly been confined to this belt, and that periods of minor true polar wander have adjusted the rotational mass imbalance caused by subduction at relatively high latitudes (Torsvik et al. 2014; Torsvik 2019). The degree-2 mantle convection pattern is further indicated by the net characteristics of plate tectonics. Conrad et al. (2013) recorded the locations of net divergence and convergence of the plates and found that two divergence poles at approximately $180^{\circ}$ were located above the LLSVPs and that two convergence poles between approximately $90^{\circ}$ from the divergence centers were above the high- $V_{\mathrm{S}}$ circumpolar (longitudinal) belt. Whereas the reconstructed divergence poles have been relatively stationary above the LLSVPs during the last $250 \mathrm{My}$, the convergence poles have moved over greater distances above the circumpolar belt. However, the global pattern suggests that the large-scale degree- 2 convection has been rather stable in this $250 \mathrm{My}$ period. The inferred lateral flow regime in the D"-zone is away from the longitudinal belt of inflow (downwelling) toward the LLSVP margins.

Seismic studies reveal that the LLSVP-margins are relatively sharp and steeply inclined, at least locally (Thorne et al. 2004; Garnero and McNamara 2008; McNamara 2019). The 
increased RMS amplitudes of lateral $V_{\mathrm{S}}$-variations in the lowermost $300 \mathrm{~km}$ compared to the rest of the deep mantle (Romanowicz 2003; Lay 2015) and recent seismic analysis (Koelemeijer et al. 2018) indicate that they are probably thermochemical features with about $300 \mathrm{~km}$-thick base layers, with a density excess sufficiently large to resist destruction by thermal buoyancy over at least hundreds of millions of years. Free-air gravity (Ishii and Tromp 1999) and tidal tomography (Lau et al. 2017) investigations suggest that the lowermost $200-300 \mathrm{~km}$ of the LLSVPs have density excesses of about $1.25 \%$ compared to the surrounding mantle. Assuming a corresponding temperature excess of $750 \mathrm{~K}$ and thermal expansion data from Wolf et al. (2015), Trønnes et al. (2019) estimated an intrinsic density excess of $2.2 \%$ and a matching bridgmanite composition containing $16 \mathrm{~mol} \%$ of the combined $\mathrm{Fe}$-components, $\mathrm{FeAlO}_{3}$ and $\mathrm{FeSiO}_{3}$. The bridgmanite of ambient depleted peridotite in the lower mantle contains about 2.3, 3.8, 0.6, and $93.3 \mathrm{~mol} \%$ of the components $\mathrm{FeAlO}_{3}$, $\mathrm{FeSiO}_{3}, \mathrm{Al}_{2} \mathrm{O}_{3}$, and $\mathrm{MgSiO}_{3}$, respectively.

Assuming an outermost core temperature of $4000 \mathrm{~K}$, the $300-400 \mathrm{~km}$ thick thermal boundary layer above the core-mantle boundary (CMB) is characterized by a strong temperature increase of about $1500 \mathrm{~K}$ from the ambient mantle adiabat of about $2500 \mathrm{~K}$ at $2600 \mathrm{~km}$ depth (e.g., Stixrude et al. 2009). The presence of post-bridgmanite in the cooler, high- $V_{\mathrm{S}}$ regions of the $\mathrm{D}$ "-zone, combined with the overall high temperatures close to the CMB, is likely to reduce mantle viscosity by three to four orders of magnitude (e.g., Nakada and Karato 2012; Dobson et al. 2019). Conceivably, the LLSVP base layer may also have low viscosity, e.g., in the form of basaltic to picritic ROC, containing post-bridgmanite. In that case, the stabilizing factor may be the degree- 2 convection pattern itself, which in turn is linked to, and probably stabilized by, the Earth's rotation (Steinberger and Torsvik 2008, 2010). Material with an appropriate density excess will be swept into the LLSVP root zones of the broad antipodal outflow creating the residual geoid heights. If the density excess is too high, the material will form a continuous thin layer across the entire CMB. If it is too low, it will be convectively dispersed. Dense bridgmanitic cumulate material with about $16 \mathrm{~mol} \%$ of the $\mathrm{Fe}$-components $\left(\mathrm{Fe} \mathrm{AlO}_{3}\right.$ and $\mathrm{FeSiO}_{3}$, see above), may be stable relative to post-bridgmanite in the lower part of the hot LLSVP base layers. As discussed in Sect. 1 below, such material possibly formed at a late-stage cumulates during the crystallization of the basal magma ocean and will have high strength and viscosity, and thereby intrinsic stability.

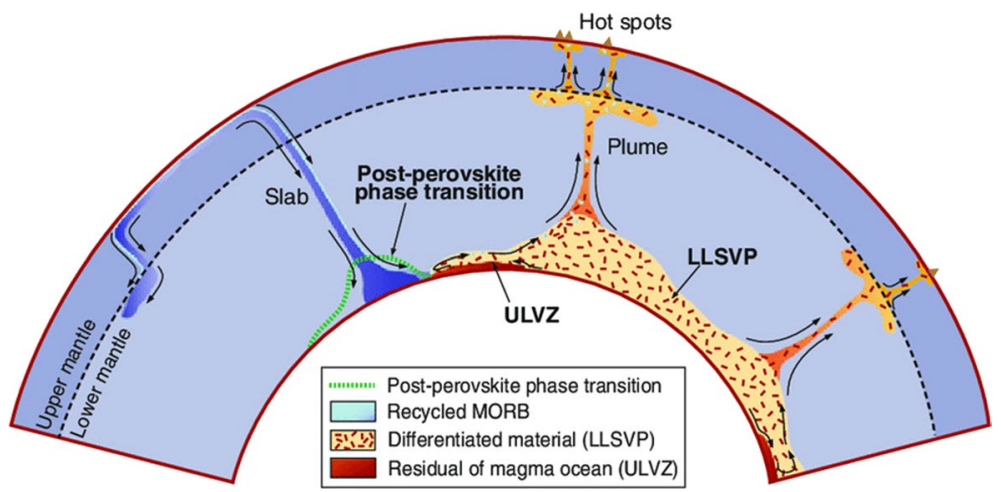

Fig. 2 Approximate and schematic equatorial section showing Earth's main structural features and domains. LLSVP large low S-wave velocity provinces, ULVZ ultra-low velocity zones. From Deschamps et al. (2015) 


\subsection{Ultra-Low Velocity Zones (ULVZs) Feeding Deep-Rooted Mantle Plumes}

Further contributions to the heterogeneity and material property gradients of the D"zone are made by thin (5-40 km thickness) and laterally patchy ultra-low velocity zones (ULVZs) in direct contact with the CMB (see Fig. 2). The $V_{\mathrm{P}}$ and $V_{\mathrm{S}}$ reductions of about 10 and 30\%, respectively, may indicate partial melt fractions of 5-10\% (e.g., Lay 2015). Alternatively, the reductions may be caused by the presence of iron-rich minerals (e.g., Karato 2014; McNamara 2019).

Most of the deep-rooted mantle plumes giving rise to large igneous provinces (LIPs) and ocean island basalt (OIB) appear to have developed and risen from sites along the LLSVP-margins (e.g., Burke and Torsvik 2004; Torsvik et al. 2006, 2010, 2016). Even kimberlites with lower mantle geochemical features appear to be related to deep-rooted plumes in the general area of the African LLSVP, although their reconstructed eruption sites are not convincingly close the LLSVP-margins (Giuliani et al. 2021). The additional coincidence of ultra-low velocity zones (ULVZs) with the inferred plume sources along the LLSVP-margins (e.g., Thorne et al. 2004; Cottaar and Romanowicz 2012; Yuan and Romanowicz 2017) indicates that focusing on the lateral D" flow also tends to concentrate low-viscosity ULVZ-materials with density exceeding that of the LLSVPs into centers of columnar upwelling.

Subducted basaltic lithologies, which have solidus temperatures of about $3870 \mathrm{~K}$ at $130 \mathrm{GPa}$, are likely to undergo partial melting once they reach the hottest parts of the D"-zone near the LLSVP-margins (e.g., Andrault et al. 2014; Pradhan et al. 2015; Baron et al. 2017; Tateno et al. 2018). In addition to the formation of dense silicate melt, Liu et al. (2016) found that a minor metallic melt fraction from the eutectic point on the Fe-C compositional join (about 2 wt.\% C; Fei and Brosh 2014) would also be generated. The melting experiments of Andrault et al. (2014), Pradhan et al. (2015), and Tateno et al. (2018), demonstrate that Ca-perovskite is the first liquidus phase and can be trapped in basaltic compositions in the lowermost mantle. The high density of residual Ca-perovskite compared to lower density seifertite $\left(\mathrm{SiO}_{2}\right)$ and $\mathrm{MgSiO}_{3}$-dominated bridgmanite, would lead to differential sinking of the densest metallic melt, intermediate-density silicate melt and less dense Ca-perovskite crystals, combined with ascent of bridgmanite and seifertite. An Al-rich Ca-ferrite-structured mineral, also present in basaltic compositions in the lower mantle, would be melt-consumed at or near the solidus. Such a disaggregation of the partially melting basaltic material would concentrate sinking Ca-perovskite and interstitial melt into the underlying ULVZs. As pointed out by Hernlund and Jellinek (2010), the low viscosity of partially molten ULVZs may induce sufficiently vigorous internal convection to prevent large-scale downward segregation of the interstitial melt, keeping ULVZs seismically homogeneous (Lay 2015). This requires that the topography of the ULVZ region is maintained by the pressure gradient caused by the convective current above that region (Karato 2014). Diffusional extraction of the FeO-component from the silicate melt to the core and diffusional delivery of the $\mathrm{SiO}_{2}$ component from the core to the ULVZs (see Sect. 1), might reduce the density of the interstitial silicate melt to that of Ca-perovskite, or even less.

Therefore, the ULVZs may represent partially leaky "windows" between the D"zone and the outer core. Such localized core-mantle exchange is supported by geochemical investigations of plume-related volcanic rocks. Recent isotopic measurements have revealed a negative correlation between the ${ }^{182} \mathrm{~W} /{ }^{184} \mathrm{~W}$ and ${ }^{3} \mathrm{He} /{ }^{4} \mathrm{He}$ 
ratios in major plume-related OIB suites (Mundl et al. 2017; Mundl-Petermeier et al. 2019, 2020; Rizo et al. 2019; Jackson et al. 2020). Radiogenic ${ }^{182} \mathrm{~W}$ is derived from short-lived ${ }^{182} \mathrm{Hf}$ with a half-life of $9 \mathrm{My}$ and has a practical lifetime of about $45 \mathrm{My}$, which implies extinction well before the giant impact with resulting Moon formation. Because lithophile Hf partitions into silicate magma oceans while siderophile $\mathrm{W}$ partitions into metallic cores, the terrestrial planetary core material segregated early has very low ${ }^{182} \mathrm{~W} /{ }^{184} \mathrm{~W}$ ratio. Plumes giving rise to OIBs with low ${ }^{182} \mathrm{~W} /{ }^{184} \mathrm{~W}$ ratios might therefore have sampled core metal, most likely via the ULVZs located in the plume root zones.

\subsection{Magma Ocean Solidification and Long-Term Preservation of Geochemical Reservoirs}

Chemical exchange between the early-formed core and whole-Earth magma ocean formed in the aftermath of the giant impact, and subsequently between the cooling and chemically evolving core and basal magma ocean (Malavergne et al. 2004; Tsuno et al. 2013; Laneuville et al. 2018) might potentially lead to extensive volumes of early refractory and bridgmanitic domains in the lower mantle (Ballmer et al. 2017; Trønnes et al. 2019; Gülcher et al. 2020). A possible stagnant low-density and low-velocity E'-layer of the outermost core, enriched in $\mathrm{O}$ and depleted in Si (Helffrich and Kaneshima 2010; Kaneshima and Helffrich 2013; Kaneshima and Matsuzawa 2015; Brodholt and Badro 2017; Kaneshima 2018) might partly represent a complementary trace of this chemical exchange.

Bridgmanite (bm) is the first liquidus phase in a wide range of peridotitic melts, from very refractory (depleted) to fertile (pyrolitic) and chondritic (i.e., bridgmanitic) compositions (Liebske and Frost 2012; de Koker et al. 2013; Ozawa et al. 2018). At pressures above $80 \mathrm{GPa}$, the bm-melt $\mathrm{Fe} / \mathrm{Mg}$ exchange coefficient $\mathrm{KD}=(\mathrm{Fe} / \mathrm{Mg})^{\mathrm{bm}} /(\mathrm{Fe} / \mathrm{Mg})^{\text {melt }}$ is 0.1 or even lower (e.g., Tateno et al. 2014). The very strong partitioning of Fe into melt compared to bridgmanite results in a bm-melt density crossover, with a neutral buoyancy level somewhere in the 1500-2200 km depth range in the whole-mantle magma ocean that formed following the giant impact (Lock et al. 2018).

High-pressure phase relations indicate thus that the solidification of the whole-mantle magma ocean would have produced large amounts of early bridgmanite-dominated cumulates, as well as later bridgmanite-dominated residues from localized remelting above the basal magma ocean (e.g., Tateno et al. 2014; Ozawa et al. 2018; Caracas et al. 2019). Such viscous material, neutrally buoyant in the middle part of LM, can be convectively aggregated into bridgmanite-enriched ancient mantle structures (BEAMS, Manga 1996a, b; Ballmer et al. 2017), located outside the margins of rising mantle columns above the LLSVPs. BEAMS is a model proposed by Ballmer et al. (2017) based on the experimental results by Girard et al. (2016) to explain the persistence of geochemical reservoirs in the lower mantle for billions of years. However, as suggested by Girard et al. (2016, see also Chen 2016), BEAMS is unnecessary to explain long-term preservation of geochemical reservoirs. BEAMS remain thus controversial. There are several points, like the existence of early refractory domains dominated by bridgmanite that have experimental evidences, but their convective aggregation into relatively large and coherent "mantle structures" is often debated.

The presence of either BMO or BEAMS is unconstrained (their presence is hypothetical). BMO was likely present when the magma ocean solidified, and it might also be present now as suggested by, e.g., Labrosse et al. (2007). The latter model is based on the 
interpretation of ULVZ. However, the problem of identifying ULVZ with a region of partial melt is discussed by Karato (2014), and an alternative model for ULVZ was proposed by Otsuka and Karato (2012). The existence of partial melt is frequently invoked to explain geophysical anomalies such as low seismic wave velocity and high electrical conductivity. Using the mineral physics observations on the influence of melt on physical properties and the physics and chemistry of melt generation and transport, Karato (2014) demonstrates that partial melt models for the geophysical anomalies of the asthenosphere are unlikely to be valid but that, in the deep upper mantle, "dehydration melting" is likely at around $410-\mathrm{km}$. In the ultra-low velocity zone in the $\mathrm{D}$ " layer, partial melt is also unlikely unless the melt density is extremely close to the density of co-existing solid minerals or if there is a strong convective current to support the topography of the ULVZ region. Compositional variation such as Fe-enrichment (e.g., Wicks et al. (2010)) is an alternative cause for the anomalies in the D" layer. It must be mentioned though that Otsuka and Karato (2012) have shown that diffusion-controlled iron enrichment is too slow and inefficient, that the core is under-saturated with oxygen, implying that the mantle next to the core is depleted in $\mathrm{FeO}$, and thus that minerals at the bottom of $\mathrm{D}^{\prime \prime}$ are likely depleted with Fe (see also Wimert and Hier-Majumder 2012). Otsuka and Karato, however, also show that ( $\mathrm{Mg}, \mathrm{Fe}) \mathrm{O}$ in contact with iron-rich liquids leads to a morphological instability, causing blobs of ironrich liquid to penetrate the oxide. Iron-rich melt could be transported 50 to $100 \mathrm{~km}$ away from the core-mantle boundary by this mechanism.

As introduced by Chen (2016), the discovery of the breakdown of ringwoodite into the denser bridgmanite and magnesiowüstite phases at $24 \mathrm{GPa}$ removed the need for a major chemical discontinuity in Earth inferred from observations of a strong seismic reflector at $660 \mathrm{~km}$ depth and a low-viscosity zone at the top of the lower mantle. Bridgmanite is believed to be the rheologically strongest phase at high pressure and high temperature among all dominant minerals in the shallower mantle, giving rise to a high viscosity of the lower mantle relative to the upper mantle and the transition low-viscosity zone. Girard et al. (2016) found that shear deformation of bridgmanite and magnesiowüstite aggregates at lower mantle conditions, that bridgmanite is substantially stronger than magnesiowüstite and that magnesiowüstite largely accommodates strain, so that strain weakening and resultant shear localization can occur in the lower mantle. Note that shear inside the mantle strongly depend on the water content (see Karato 2013, for a review). Shear localization in the lower mantle has an impact on the mantle dynamics. This would explain the preservation of long-lived geochemical reservoirs there.

Another interesting idea in order to explain the so-called core signature or core fingerprint, is to consider models including diffusional transport of core-related elements at the CMB. Hayden and Watson $(2007,2008)$ suggested that mixing of outer core material back into the mantle following core formation might be responsible for the siderophile element ratios observed in upper mantle rocks. They considered grain-boundary mobility and demonstrated this possibility using laboratory experiments. They show in their experiments that grain-boundary diffusion resulted in significant alloying, enabling calculation of grainboundary fluxes.

Almost in parallel, Kanda and Stevenson (2006, see also Otsuka and Karato 2012) worked on liquid metal from the outer core may infiltrate across the CMB into the lower mantle and solidify. Brandon and Walker (2005) also consider that exchange with the surrounding mantle may exist and then drain back into the outer core, mentioning reaction zones at the CMB. For this chemical exchange between the core and the mantle, two types of models have been proposed, mixing of core metal into plume sources of the mantle and equilibrium exchange in reaction zones between core metal and the mantle above the CMB. 
Isotopes are a powerful tool to detect and characterize deep Earth domains that have remained relatively isolated and protected from convective destruction and mixing. For instance, because primordial-like high ${ }^{3} \mathrm{He} /{ }^{4} \mathrm{He}$ ratios are correlated with elevated plume flux (e.g., Jackson et al. 2017, 2021), the associated core-derived negative ${ }^{182} \mathrm{~W} /{ }^{184} \mathrm{~W}$ anomaly relative to Earth's common W isotope composition, suggests that mainly the most vigorous plumes are able to sample core metal entrained in the ULVZs. Although the primordial-like He composition conceivably also could be a core signal (e.g., Porcelli and Halliday 2001; Porcelli and Elliott 2008), it is more likely caused by the entrainment of more or less refractory bridgmanitic material into the plume conduit during transit through the lower mantle. Whereas Trønnes et al. (2018) suggested entrainment of very refractory BEAMS-material at mid-mantle depths to explain the primordial-like He-isotope signal, Jackson et al. (2020) and Giuliani et al. (2021) favor entrainment of more iron-rich magma ocean cumulates located at the base of the LLSVPs.
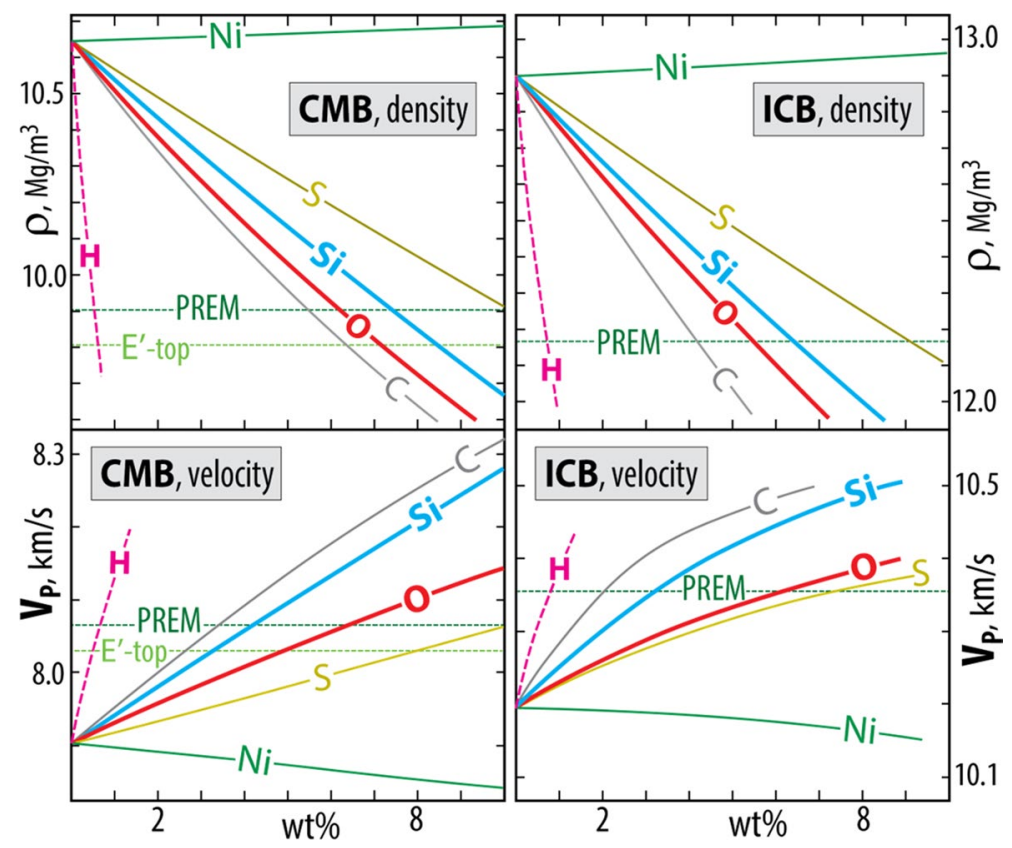

Fig. 3 Density (upper panels) and velocity (lower panels) of six molten Fe-dominated binary alloys as a function of wt.\% of the alloying element at the approximate conditions of the core-mantle boundary (CMB, $136 \mathrm{GPa}$ and $4300 \mathrm{~K}$ ) and inner core boundary (ICB, $229 \mathrm{GPa}$ and $6300 \mathrm{~K}$ ), based on first principles atomistic calculations. The curves for the alloys with C, S, Si, and O are from Badro et al. (2014) and Brodholt and Badro (2017). The Fe-H curves are based on the Umemoto and Hirose (2020) computations, but adjusted vertically to the density and velocity of pure Fe based on Badro et al. (2014) and Brodholt and Badro (2017). The densities and velocities of PREM (Dziewonski and Anderson 1989) and the top of the outermost E'-layer are shown by green horizontal dashed lines. The E'-layer velocity is from the KHOMC seismic velocity model of Kaneshima and Helffrich (2013) and Kaneshima (2018) and the E'-layer density is calculated by Trønnes et al. (2019, Table 3), based on Fig. 2b of Brodholt and Badro (2017) 


\section{Core Composition, Structure and Dynamics}

\subsection{Compositional Features of Earth's Core}

The stability of the iron atom nucleus results in high cosmic abundance and excess iron abundances relative to other major elements like $\mathrm{O}, \mathrm{Si}, \mathrm{Mg}, \mathrm{Ca}, \mathrm{Al}$, and $\mathrm{Ti}$, which form silicate and oxide minerals in the mantle rocks of the Earth and the other terrestrial (Earthlike) planets. During accretion and differentiation, the excess Fe segregates to form dense metallic cores. Depending on the pressures and temperatures at which metal and silicate segregate and equilibrate, iron-loving (siderophile) elements, including $\mathrm{Ni}$ and $\mathrm{Co}$, as well as a selection of elements lighter than iron, also enter the Fe-dominated core alloys. The presence of light elements in Earth's core is clear from Fig. 3, which shows the density deficit and velocity excess of PREM (Dziewonski and Anderson 1981) for the Earth's presentday molten outer core relative to molten pure iron. The observed density deficit implies that the outer core must contain a certain amount of one or more of the light elements $\mathrm{Si}, \mathrm{S}$, O, C, and/or H (e.g., Poirier 1994). The exact light element composition of the outer core alloy (as well as of the inner core, which also exhibits a small density deficit) is still controversial, with Hirose et al. (2013) listing the number of papers supporting each element ranging from $\sim 30$ for $\mathrm{C}$ and $\mathrm{H}, \sim 70$ for $\mathrm{O}, \sim 80$ for $\mathrm{Si}$, and $\sim 100$ for $\mathrm{S}$.

Hirose et al. (2021) further review the properties and phase rleeations of iron alloys under high-pressure and high-temperature conditions relevant for the Earth's core and provide also the likely ranges of compositions $(\mathrm{Fe}+5 \% \mathrm{Ni}+1.7 \% \mathrm{~S}+0-4.0 \% \mathrm{Si}+0.8-5$. $3 \% \mathrm{O}+0.2 \% \mathrm{C}+0-0.26 \% \mathrm{H})$. As they mention, the exact composition of the core remains unknown.

Although the Earth's core composition is still open to debate, its physical properties, in the form of density and bulk sound velocity profiles (e.g., the PREM), are reasonably well known and provide important constraints. First principles atomistic calculations by Badro et al. (2014), Brodholt and Badro (2017) and Umemoto and Hirose (2020) have established the density and bulk sound velocity variation as a function of concentration for the six most relevant Fe-dominated binary alloys (summarized in Fig. 3). Badro et al. (2014) concluded that $\mathrm{O}$ is required as the main light core element, and Badro et al. (2015) favored a core with 3-5 wt.\% O and 2-4 wt\% Si to fulfil the PREM constraints on density and velocity through the entire outer core. In addition to $\mathrm{O}$ and $\mathrm{Si}$, the core is likely to contain minor amounts of other light elements like $\mathrm{H}, \mathrm{S}$, and $\mathrm{C}$. There are caveats to the computational work on the properties of materials at extreme conditions (as outlines in Sect. 5). Experimental studies of binary Fe-light element systems (which are also very challenging) are increasingly reaching pressure-temperature conditions directly relevant for the CMB, and thermodynamic models of these binary systems based on a combination of computational and experimental data are starting to be developed (e.g., review in Komabayashi 2021).

As shown in Fig. 3, an H-content of $0.5-0.8$ wt.\% could conceivably explain the entire mismatch between the density and velocity of pure liquid Fe from the corresponding PREM values. Recently determined partition coefficients for $\mathrm{H}$ between metal melt and silicate melt have yielded a range of values from below unity (lithophile $\mathrm{H}$ ) in experiments with "natural," complex silicate melts and core compositions at moderate pressures up to $20 \mathrm{GPa}$ (Clesi et al. 2018; Malavergne et al. 2019) to above unity (siderophile $\mathrm{H}$ ) for the first principles thermodynamic integration in simulations with pure Fe-metal and silicate melt of $\mathrm{MgSiO}_{3}$ composition up to CMB conditions (Li et al. 2020; Yuan and SteinleNeumann 2020). The partition coefficients, using ab initio methods might become slightly 
lower (closer to unity) for more complex silicate melts containing components like ferrous and ferric iron and aluminum oxides. Even with the rather high partition coefficient, $D_{\mathrm{H}}^{\text {metal/silicate }}$ of about 15 at CMB conditions, derived in the Li et al. (2020) simulations, it is likely that the core contains less than about $0.1 \mathrm{wt} . \% \mathrm{H}$. With a $D_{\mathrm{H}}{ }^{\text {metal/silicate }}$ of 15 , a concentration of $0.1 \mathrm{wt} . \% \mathrm{H}$ in the core would correspond to 13 times the surface ocean inventory of $\mathrm{H}$ ( $\mathrm{Li}$ et al. 2020) and a bulk mantle concentration of about $1200 \mathrm{ppm} \mathrm{H}_{2} \mathrm{O}$. The experimental determination of $\mathrm{H}$ partitioning at $\mathrm{CMB}$ conditions is extremely challenging. Although ab initio calculations are generally more straightforward, the limitations imposed by simulation cell size restrict the compositional complexity, making it difficult to model a realistic silicate melt.

Whereas near-eutectic melt fractions of sulfur-bearing metal are likely to contribute to early planetesimal cores under relatively oxidizing conditions and low to moderate pressures (Yoshino et al. 2003; Walter and Trønnes 2004; Stewart et al. 2007; Trønnes et al. 2019), Earth accreted largely from reduced material of enstatite chondritic type. If the Earth accreted one or more Mercury-like planetary embryos, its core might have incorporated some sulfide (Wade and Wood 2016; Wohlers and Wood 2017; Greenwood et al. 2018).

The accretion of strongly reduced sulfide-bearing materials in the form of planetesimals and planetary embryos of composition similar to that of enstatite chondrites and aubrites (Wade and Wood 2016; Greenwood et al. 2018), probably led to incorporation of U, as well as $\mathrm{Nd}$ and $\mathrm{Sm}$ with elevated $\mathrm{Nd} / \mathrm{Sm}$ ratio relative to chondrites and the bulk silicate Earth (Wohlers and Wood 2017). Based on recent indications of very high thermal conductivity of the outer core alloy (see Sect. 3.2), some radioactive heating of the core seems required to drive the geodynamo. It is also likely that minor amounts of other lithophile elements like $\mathrm{Mg}$ and $\mathrm{Al}$ were incorporated into the hot protocore and that their subsequent exsolution as $\mathrm{MgO}, \mathrm{MgSiO}_{3}$, and $\mathrm{Al}_{2} \mathrm{O}_{3}$ and buoyant rise into the mantle magma ocean would contribute to the earliest geodynamo (e.g., Badro et al. 2016; Trønnes et al. 2019; Helffrich et al. 2020).

\subsection{Core Evolution and a Possible Stagnant E'-Layer}

Several studies have recognized that the seismic P-wave velocity of the outermost 200-500 km of the core decreases outwards more than PREM (Lay and Young 1990; Garnero et al. 1993; Helffrich and Kaneshima 2010; Kaneshima and Helffrich 2013; Kaneshima and Matsuzawa 2015; Kaneshima 2018 and Irving et al. 2018). Brodholt and Badro (2017) introduced the term $\mathrm{E}^{\prime}$ for this layer. In the seismic KHOMC model of Kaneshima and Helffrich (2013), the outward velocity deficiency relative to PREM starts from zero at $445 \mathrm{~km}$ depth below CMB and reaches $35 \mathrm{~m} / \mathrm{s}(0.43 \%)$ at the CMB. Several additional studies have attempted to model the dynamics and possible stability of such a layer (e.g., Buffett 2010; Buffett and Seagle 2010; Gubbins and Davies 2013; Glane and Buffett 2018). For instance, Glane and Buffett (2018) have studied a new coupling mechanism between the core and the mantle to explain length-of-day (LOD) variations that relies on the presence of stable stratification at the top of the core. Glane and Buffett mention that steady flow of the core over boundary topography promotes radial motion, but buoyancy forces due to stratification oppose this motion. Steep vertical gradients develop in the resulting fluid velocity, causing horizontal electromagnetic forces in the presence of a radial magnetic field and an associated pressure field that exerts a net horizontal force on 
the boundary. Recent experimental and ab initio theoretical determinations of the electrical and thermal conductivities of iron and several relevant outer core alloys (e.g., de Koker et al. 2012; Pozzo et al. 2012; Gomi et al. 2013; Gomi and Hirose 2015; Ohta et al. 2016) show that they are considerably lower than those of previous geodynamo models (Stacey and Loper 2007). These results may require additional geodynamo power from core radioactivity and early exothermic transfer of buoyant core components like $\mathrm{SiO}_{2}, \mathrm{MgO}$, and $\mathrm{Al}_{2} \mathrm{O}_{3}$ to the magma ocean (see Sect. 3.3). Some of these components, as well as $\mathrm{MgSiO}_{3}$, may also crystallize at greater depth prior to buoyant rise, producing convective power in combination with the denser sinking liquid depleted in the light components (Badro et al. 2016; Hirose et al. 2017; Trønnes et al. 2019; Helffrich et al. 2020). Prior to inner core growth, yielding thermal and chemical convective power at great depth, such additional sources of geodynamo power seem necessary. The onset of inner core growth is commonly estimated to be in the 1.6-1 Ga range (e.g., Nimmo 2015).

The high outer core thermal conductivity supports the notion that the top of the outermost core may contain a chemically and thermally stratified layer (e.g., Pozzo et al. 2012). The existence of such a layer changes the nature of the waves and motions inside the core. Buffett (2014) has examined the consequences of the presence of the $E^{\prime}$ layer for geomagnetic fluctuations. He used the magnetic field observations at the Earth's surface propagated down to the $\mathrm{CMB}$ and considered a generalization of the torsional oscillations in the core, the MAC waves that arise from the interplay between magnetic, Archimedes and Coriolis (MAC) forces. He found that for a stably stratified core, waves with a suitable period to explain the observed fluctuations could appear. Hernlund and McNamara (2015) reviewed the merits of a stably stratified E'-layer, in spite of the very low viscosity of the core fluid. The high thermal conductivity (e.g., Pozzo et al. 2012) will generally suppress convection and the low viscosity will also reduce the viscous entrainment. A stably stratified and conducting E'-layer may even strengthen and stabilize the geodynamo which is mainly generated in the middle to lower parts of the convecting core (Sreenivasan and Gubbins 2008; Hernlund and McNamara 2015).

An important requirement for such a gradational layer to be stagnant over time is a reduced intrinsic density relative to the underlying convecting outer core. As expected, each of the light elements causes density deficits, but each of them also results in increased, rather than decreased, $V_{\mathrm{P}}$, contrary to observations (see Fig. 3). As pointed out by Brodholt and Badro (2017), however, a partial replacement of one light element by another one, might give a suitably combined reduction in density and velocity. Because $\mathrm{O}$ decreases the velocity and decreases the density more than $\mathrm{Si}$, a partial replacement of $\mathrm{Si}$ by $\mathrm{O}$ from the outermost convecting core can yield the $V_{\mathrm{P}}$ deficit of the E'-layer. Trønnes et al. (2019) used the KHOMC deviation from PREM, combined with the mineral physics data of Brodholt and Badro (2017), to perform mass balance modeling of the $\mathrm{E}^{\prime}$-layer generation by transfer of $\mathrm{SiO}_{2}$ from the outermost convecting core to the basal magma ocean and $\mathrm{FeO}$ in the opposite direction. The resulting $\mathrm{E}^{\prime}$-layer grades from $3.0 \mathrm{wt} . \% \mathrm{O}$ and $3.6 \mathrm{wt} . \% \mathrm{Si}$ and no density and velocity deficits at $445 \mathrm{~km}$ depth to $6.7 \mathrm{wt} . \% \mathrm{O}$ and $0.4 \mathrm{wt} \%$ Si to the required density and velocity deficits of 0.98 and $0.43 \%$, respectively, at the CMB.

\subsection{Inner Core, Thermal State and Core Dynamics}

As explored further in Sect. 5, experimental and ab initio theoretical investigations to determine the high-pressure, high-temperature phase diagram of Fe and thereby the structure of the stable solid phase of the inner core are particularly challenging, largely due to 
the extreme temperature and pressure conditions. Such experiments and atomistic simulations provide melting temperature, rheological properties, equation of state, and electrical and thermal conductivities (e.g., Hirose et al. 2013; Vocadlo 2015; and references in Sect. 3.1). Laser-heated diamond cell experiments (see Sect. 5) have reached temperatures and pressures of $5500 \mathrm{~K}$ and $407 \mathrm{GPa}$, respectively (Tateno et al. 2012; see review in Komabayashi 2021). A recent investigation of the melting curve of pure iron, using diamond anvil cell resistance heating at pressures up to $290 \mathrm{GPa}$ (Sinmyo et al. 2019), resulted in a curve which is about $600 \mathrm{~K}$ below that of Anzellini et al. (2013), determined by laserheating. A lower melting curve for iron at core conditions, combined with recent result indicating considerably lower solidus temperatures for peridotite at the lowermost mantle conditions (Nomura et al. 2014; Kim et al. 2020) compared to previous determinations, might possibly lead to a reduction of the average CMB temperature estimates from values of 4200-4300 K (e.g., Nimmo 2015; Vocadlo 2015) to values in the 3600-3800 K range.

Accurate knowledge of the Fe crystal structure at extreme conditions is important for estimating the physical properties such as compressibility of the inner core. In addition, it may help to understand the origin of seismic anisotropy and the dynamics in the inner core that has been proposed from the analysis of seismic waves traveling through the inner core (e.g., Souriau 2007). In spite of some controversy, most recent studies indicate that the hexagonally close-packed (hcp) crystal structures of either pure Fe or solid alloys in the $\mathrm{Fe}-\mathrm{Si}, \mathrm{Fe}-\mathrm{C}$. and $\mathrm{Fe}-\mathrm{H}$ systems are stable at inner core conditions (e.g., Tateno et al. 2010, 2012, 2015; Stixrude 2012; Mashino et al. 2019). In contrast, Dubrovinsky et al. (2007) and Belonoshko et al. (2017) favored the body-centered cubic (bcc) structure for Fe or an appropriate Fe-Ni alloy. Recently, Kato et al. (2020) also found that a possible FeH-dominated inner core would have face-centered cubic (fcc) crystal structure.

The thermal evolution of the Earth is driven by the decay of radiogenic isotopes and by the slow secular cooling from a temporal maximum at about $3 \mathrm{Ga}$ (e.g., Herzberg et al. 2016). The thermal and compositional evolution of Earth's core is also related to the inner core growth, from a likely onset about 1.6-1.0 Gy ago (Nimmo 2015). The outer core composition changes continuously as the inner core grows, precipitating an iron-rich alloy with a composition differing (likely more Fe-rich and possibly close to the Fe-Si join) from the evolving outer core composition. The release of latent heat of crystallization and enrichment in light elements (e.g., O) in the liquid alloy adjacent to the edge of the growing inner core have provided important thermal and compositional buoyancy, driving outer core convection and powering the geodynamo during the last 1.6-1.0 Gy.

The density jump at the present-day inner core boundary as provided by seismology (PREM model, Dziewonski and Anderson 1981) is as large as $600 \mathrm{~kg} \mathrm{~m}^{-3}$, which requires enrichment in light element(s) in the outer core relative to the inner core. This value has been recently re-evaluated and the values are ranging from 420 to $820 \mathrm{~kg} \mathrm{~m}^{-3}$, recognizing the possible influence of lateral heterogeneities in the inner core and seismic noise (e.g., Hirose et al. 2013; Krasnoshchekov et al. 2019; Wong et al. 2021).

\section{Core-Mantle Boundary}

\subsection{CMB from Seismology}

The properties of the core-mantle boundary $(\mathrm{CMB})$ region can be obtained mostly from seismology, based on either compressional (P) or shear (S) wave travel times (e.g., Morelli 
and Dziewonski 1987). Seismic phases that have been used for this purpose (e.g., Koelemeijer et al. 2016, 2017) include PKP (compressional waves traveling through the outer core) and PKIKP (compressional waves traveling through both the outer and inner core). Other approaches include studying seismic normal modes splitting (e.g., Li et al. 1991; Ishii and Tromp 2001; seismic normal modes are the modes with periods less than an hour and related to the elastic restoring force in the mantle; they are generated after earthquakes) and seismic waves that reflect at the metal-rock interface in the $\mathrm{CMB}$ ( $\mathrm{ScS}, \mathrm{PcP}$ seismic phases, e.g., Boschi and Dziewonski 1999; Vasco et al. 1999; Soldati et al. 2003; Boschi et al. 2013).

Recently, mantle normal mode observations have been shown to be very useful to constrain properties and processes of the $\mathrm{CMB}$ as well. In order to constrain the density and viscosity of the mantle close to the $\mathrm{CMB}$, one can use normal modes whose frequencies are set by the density and wavespeeds close to either side of the CMB, called Stoneley modes ${ }_{2} \mathrm{~S}_{16}$ and ${ }_{3} \mathrm{~S}_{36}$ (Koelemeijer et al. 2017). The predicted effects of the presence of LLSVPs with varying density excesses compared to the surrounding lower mantle can be compared with observations. Using this approach, Koelemeijer et al. (2017) showed that relatively low excess densities of LLSVPs are more probable, which according to the authors, would explain the excess of ellipticity (i.e., the increase in the equatorial radius with respect to the value deduced from hydrostatic equilibrium) and the zones of ascent above the LLSVPs.

\subsection{CMB from Dynamics}

CMB topography can also be obtained from dynamical considerations, considering that the mantle contains density anomalies as seen from the seismic tomography, and computing the associated loading on the CMB. The CMB topography mainly shows long-wavelength features related to the subduction of plates deep into the mantle and as actively upwelling material rising in deeply rooted hotspots or, in the upper mantle, as passively upwelling material underneath mid-ocean ridges. Numerical studies have shown that these longwavelength features are mainly driven by the mass anomalies at the bottom of the mantle, with the CMB topography responding similar to isostasy. The numerical dynamic studies have also shown that the amplitudes of these topographic variations depend on the viscosity/anelasticity at the bottom of the mantle used for these internal loading computations (e.g., Defraigne et al. 1996; Dehant and Wahr 1991). Numerical modeling of mantle flow and the induced dynamic CMB topography aids in the interpretation of these observational constraints (e.g., Forte et al. 1995; Forte and Mitrovica 2001; Forte 2007; Yoshida 2008; Steinberger and Holme 2008; Simmons et al. 2009; Lassak et al. 2010; Soldati et al. 2012, 2013; Liu and Zhong 2015; Deschamps et al. 2018). Some of these studies show significant differences in model outcomes (e.g., Soldati et al. 2012) and some suggest that all available data should be inverted together to better constrain the CMB topography (e.g., Colombi et al. 2014; Simmons et al. 2010). These authors had the idea to resolve the 3D image of the mantle and $\mathrm{CMB}$, by combining multiple data types. They use the predicted velocity structure from the model where the seismic constraints are weak, filling in the gaps. The model so obtained, termed GyPSuM ( $\mathrm{G}=$ Geodynamic, $\mathrm{y}, \mathrm{P}=\mathrm{P}$ waves, $\mathrm{S}=\mathrm{S}$ waves, $\mathrm{u}$, $\mathrm{M}=$ Mineral physics), provides mantle wave speeds and densities. One sees in the literature several approaches, either considering thermal models for the interpretation of the densities at the bottom of the mantle or thermochemical models.

Inferences for the CMB that can be derived from the above-mentioned studies are the following: 
- For density in the bottom of the mantle, average models consistently identify two areas of dense anomalies; one located below Southern Africa (centered on Angola), roughly in the core of the LLSVP imaged in seismic velocity. The other one is found under the North Pacific (close to Hawaii), located more on the edge of the LLSVP as imaged in seismic velocity.

- Seismic observations, Stoneley modes (Koelemeijer et al. 2017) and tidal measurements (Lau et al. 2017) show similar features, summarized in the paragraphs on the mantle of this article. There we show that, to unravel the nature of the lower mantle features, knowledge of more than one elastic parameter is needed, i.e., constraints on $V_{\mathrm{P}}$ are required in addition to $V_{\mathrm{S}}$. All data point to the conclusion that LLSVPs would be chemical. Although unique interpretations are difficult, as explained in our conclusion in Sect. 2.3. At this step, we also mention a comparison with the recent work by Deschamps et al. (2018) suggesting that strongly thermochemical models are inconsistent with current seismological models.

- There is no convergence toward a global model of the bottom mantle anomalies to derive a topographic map of the CMB unambiguously. One of the avenues for finding constraints or getting a better precision close to the CMB is the use of the seismic normal modes called the Stoneley modes. These models are thus often restricted to using an initial model that does not include any lateral heterogeneity (model of PREM), which explains the under-representations of the models of normal modes.

- Topography models mostly show elevated topographies under the Pacific and Africa, but details differ between models. Almost all models have a peak-to-peak amplitude below $5 \mathrm{~km}$ for degree 2 .

It is thus important to develop models based on an increase in the variety of data and of the amount of data on which to base an interpretation. It is interesting to develop models not only based on propagation speeds of seismic waves or reflected and refracted seismic waves, but as well on normal modes, on geodetic data and on the use of gravimetry to detect mass anomalies present in the mantle. At this point, it is still crucial to develop robust models of $\mathrm{CMB}$ topography that are compatible with such a large range of data.

\subsection{CMB from Geodesy}

In parallel, the CMB topography, and its flattening in particular, has been constrained from geodetic data, i.e., from length-of-day variations (e.g., Hide and Horai 1968; Jault and Le Mouël 1990) as well as from the nutations (e.g., Gwinn et al. 1986; Mathews et al. 2002). The latter are sensitive to the core-mantle boundary flattening and coupling mechanisms (see Rekier et al., 2021). Geomagnetic field data analysis can also provide important ancillary clues on the CMB location and its topography (e.g., Glatzmaier and Roberts 1996; De Santis and Barraclough 1997), although the associated resolution is much lower than that provided by seismological studies.

Finally, yet importantly, it must be mentioned that the outer core viscosity is similar to that of liquid water. In addition to generating the magnetic field, the outer core undergoes a lot of external forcing from external gravitational interactions as well as from its silicate container: the mantle undergoes convection deforming the core-mantle boundary, the outer core rotates, and it changes its orientation in space.

At seasonal, interseasonal, annual, inter-annual, decadal, and interdecadal timescales, one sees consequences in Earth rotation changes (see Rekier et al., 2021). One considers 
Fig. 4 Geometry for the free core nutation definition

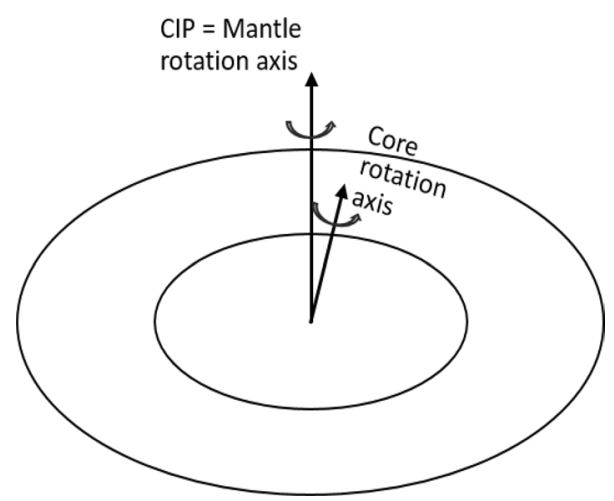

essentially inertial waves and rotation modes in the case of length-of-day variations and nutations and we see effects of these modes. Inertial waves, also known as inertial oscillations, are a type of wave possible in rotating fluids. The restoring force for inertial waves is the Coriolis force (Rekier et al. 2019, 2020). There are many waves that are more or less damped, and that show different repartitioning of the energy between the core and the mantle (Triana et al. 2019, 2021).

For nutation (see Rekier et al., 2021), this includes the effects of the Free Core Nutation $(\mathrm{FCN})$ and to a minor extent the inertial waves. The FCN is a rotational normal mode that exists if one excites an angle between the rotation axes of the core and the mantle (see Fig. 4).

It involves the fluid pressure acting on an ellipsoidal core-mantle boundary. One can compute the first approximation of its frequency in a frame tied to the Earth $\sigma_{\mathrm{FCN}}$ from the Liouville equations describing the angular momentum conservation equations of the global Earth and the liquid core (e.g., Sasao et al. 1980; Dehant and Mathews 2015):

$$
\sigma_{\mathrm{FCN}}=-\Omega\left(1+\frac{A\left(\alpha_{\mathrm{f}}-\kappa\right)}{A_{\mathrm{m}}}\right)
$$

where $\Omega$ is the Earth's angular velocity, $A_{\mathrm{m}}$ and $A$ are the moments of inertia of the mantle and of the whole Earth, respectively, $\alpha_{\mathrm{f}}$ is the dynamical flattening of the core, and $\kappa$ is the so-called compliance taking into account the deformation of the core-mantle boundary. The normal mode depends on the flattening of the core, the core deformation and the mass repartition inside the core and the mantle. Considering damping at the $\mathrm{CMB}$, the frequency of the FCN can be written

$$
\sigma_{\mathrm{FCN}}=-\Omega\left(1+\frac{A\left(\alpha_{\mathrm{f}}-\kappa+K_{\mathrm{CMB}}\right)}{A_{\mathrm{m}}}\right)
$$

where $K_{\mathrm{CMB}}$ is the coupling constant at the CMB involving all the coupling mechanisms at the CMB such as electromagnetic, viscous or topographic coupling. One also uses the FCN frequency in inertial space $\sigma_{\mathrm{FCN}}^{\prime}$, using the link

$$
\sigma=-\Omega+\sigma^{\prime}
$$

between the inertial space frequency $\sigma^{\prime}$ and the frequency in a frame tied to the Earth $\sigma$ : 


$$
\sigma_{\mathrm{FCN}}^{\prime}=\Omega+\sigma_{\mathrm{FCN}}=-\Omega\left(\frac{A\left(\alpha_{\mathrm{f}}-\kappa\right)}{A_{\mathrm{m}}}\right)
$$

The FCN induces resonances in the nutation amplitudes. The nutation amplitude $\eta\left(\sigma^{\prime}\right)$ at frequency $\sigma^{\prime}$ can be computed from the rigid-Earth nutation $\eta_{\text {rigid }}(\sigma \prime)$ and the transfer function $\operatorname{TF}(\sigma)$.

$$
\eta\left(\sigma^{\prime}\right)=\operatorname{TF}(\sigma) \eta_{\text {rigid }}\left(\sigma^{\prime}\right)
$$

The transfer function is function of the FCN frequency

$$
\operatorname{TF}\left(\sigma \text { or } \sigma^{\prime}\right)=\frac{-k A}{A_{\mathrm{m}}}-\frac{(1+k) A}{A_{\mathrm{m}}\left(\sigma-\sigma_{\mathrm{CW}}\right)}+\frac{A_{\mathrm{f}} \sigma_{\mathrm{FCN}}^{\prime}}{A_{\mathrm{m}}\left(\sigma^{\prime}-\sigma_{\mathrm{FCN}}^{\prime}\right)} \cong \frac{A}{A_{\mathrm{m}}}+\frac{A_{\mathrm{f}} \sigma_{\mathrm{FCN}}^{\prime}}{A_{\mathrm{m}}\left(\sigma^{\prime}-\sigma_{\mathrm{FCN}}^{\prime}\right)}
$$

in the retrograde diurnal approximation in a frame tied to the Earth, where $k$ is the tidal Love number for the mass repartition induced by deformation and $\sigma_{\mathrm{CW}}$ is the Chandler Wobble frequency, and where we see that the transfer function for nutations contains a resonance at the FCN frequency. None of the parameters therein like $A_{\mathrm{m}}$ are related to the core. However, the FCN frequency and the damping as well as the core moment of inertia are difficult to disentangle. This can only be done with the help of modeling. A discussion on the importance of these parameters in terms of core properties are provided in the chapter of Rekier et al. of this book (see Eq. (4) therein as well as the discussion in the conclusion). Of particular interest is the core dynamical flattening $\alpha_{\mathrm{f}}$ that enters Eq. (1) or (2). The observation provides a linear combination of the core dynamical flattening $\alpha_{\mathrm{f}}$, the compliance $\kappa$ related to the mantle elastic properties, and the complex coupling constant $K_{\mathrm{CMB}}$. In order to reach a value for $\alpha_{\mathrm{f}}$, a hypothesis on the coupling mechanisms at the CMB must be done. When no additional torque is considered at the CMB except the dynamic pressure torque on the topography as performed in Herring et al. (1991) or Mathews et al. (1991a, b), the dynamical flattening of the core can be evaluated and has been shown to correspond to an equatorial radius of the core $500 \mathrm{~m}$ larger than the value from hydrostatic equilibrium. Mathews et al. (2002, see also Zhu et al. 2021) have further considered the existence of an electromagnetic torque at the $\mathrm{CMB}$ and have reduced this value to $350 \mathrm{~m}$.
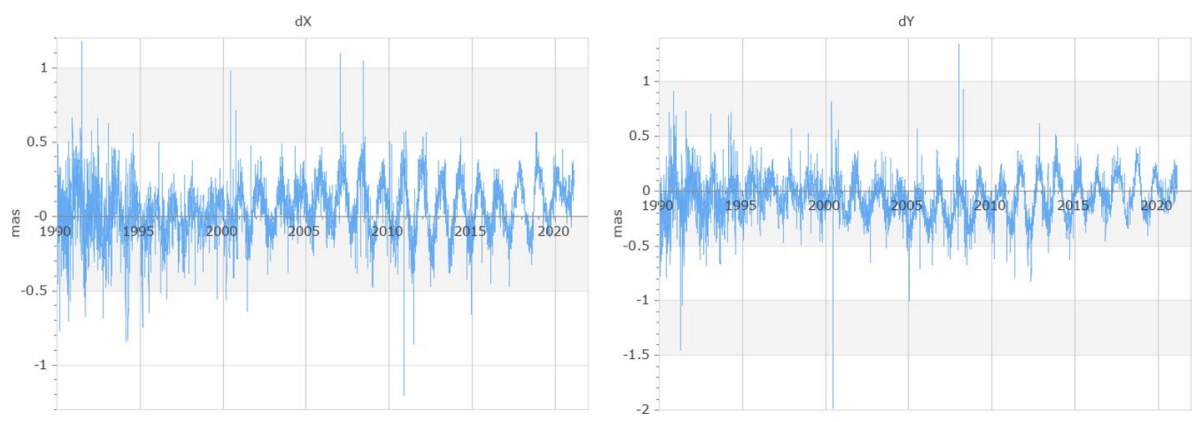

Fig. 5 Residuals (given in milliarcsecond (mas) as a function of time) of the CIP (Celestial Intermediate Pole) position ( $\mathrm{d} X$ and $\mathrm{d} Y$ ) between the observed nutation (observed by Very Long Baseline Interferometry, VLBI) and the most accurate model that exists at present, over the past three decades. This figure has been built from the IERS-Observatoire de Paris website (https://hpiers.obspm.fr/eop-pc/index.php?index=orien tation\&lang=en), for the years 1990-2021. See also Rekier et al. (2021) 
There is, in addition, an excitation of the free mode, which could also help constrain core properties (Zhu et al. 2021). Figure 5 shows the evolution of the free mode excitation as observed in the VLBI data over the past three decades. The analysis of this contribution to the nutation in terms of core physics is, however, more difficult as we do not know the excitation period, amplitude and phase. As mentioned in Zhu et al. (2021) it is possible that the there is a beating between the FCN period and another frequency most probably related to an inertial mode. It is also possible that the excitation period, most probably coming from the atmosphere, could change as a function of time. The best reliable results concerning nutation observation are coming from the forced nutations.

Together with Earth rotation changes (see Rekier et al., 2021), the nutations can provide additional geodetic information about core properties and processes such as the coupling mechanisms acting at the core-mantle boundary and at the inner core boundary. Details are provided in Rekier et al. (2021).

The study of LOD variations at decadal timescale can also bring insight on the coremantle boundary coupling mechanisms as explained by Gross (2007 and 2015; see also Buffett 2010; Buffett and Seagle 2010; Buffett 2014; Glane and Buffett 2018; as well as Gillet et al. 2017, 2021).

\subsection{Torques at the CMB}

Understanding what is going on at the CMB is crucial as well. As detailed in Rekier et al. (2021), there are different coupling mechanisms between the core and the mantle: the topographic torque (or pressure torque) related to the pressure acting on a bumpy boundary (e.g., Hide 1977), the gravitational torque, the viscous torque, and the electromagnetic torque. In terms of processes that could take place at the $\mathrm{CMB}$, one may consider the existence of percolation (Mandea et al. 2015).

\section{High-Pressure Experiments to Constrain Core and Mantle Properties}

Quantitative interpretations of the geochemical, seismological, and geodetic observations related to the deep Earth discussed in the previous sections hinge on the availability of experimental measurements of the high-pressure and high-temperature physical and chemical properties of silicate and metal solid phases as well as silicate and metal melts. Some of the main techniques available for such property measurements are reviewed in this section.

Some of these experiments, particularly those dealing with measurements of the equilibrium major and trace element composition of co-existing phases, can be performed in high-pressure laboratories situated on university campuses or research institutes. Such experiments require achieving stable, hydrostatic pressure conditions for the duration of the experiment (which typically lasts between minutes and $24 \mathrm{~h}$ depending on the temperatures involved). These experiments are ended by rapidly (typically in 10-30 s) lowering sample temperatures from $>1000 \mathrm{~K}$ to room temperature, "freezing in" chemical compositions that were set at the high temperature of the experiment, followed by decompression. Such experiments are typically followed by analyses using state-of-the-art microbeam techniques, enabling detailed chemical compositional measurements of the run products.

Other experiments, especially those related to physical property measurements, require so-called in situ techniques, probing sample properties while the sample is experiencing high-pressure and/or high-temperature conditions. These experiments are typically 
performed using a range of synchrotron X-ray diffraction and absorption, neutron-based techniques. Facilities that combine high-pressure equipments capable of generating static high pressures used by deep Earth scientists with these analytical capabilities are at present only available at large-scale facilities, including around a dozen major centers in the USA (e.g., APS and NSLS), Europe (e.g., ESRF in France, PETRA-III at DESY in Germany, Diamond in the UK, and PSI in Switzerland), Japan (e.g., SPring-8 and the Photon Factory), and China (e.g., SSRF).

High-pressure, high-temperature experiments are also increasingly performed in silico, using the first principles molecular dynamics simulations. Major advantages of these include that they can uniquely provide an atom-scale view of processes and properties, and that they can reach pressures and temperatures out of reach of experimental equipment. A disadvantage is that simulating multi-component systems representing lower mantle or core compositions can still be prohibitively expensive computationally (leading to many simulation studies focusing, for example, on end member compositions such as pure $\mathrm{MgSiO}_{3}$ for bridgmanite). Another issue is that although these in silico approaches provide accurate information on relative changes in properties under changing conditions (for example, the calculated change in density of a mineral as a function of pressure compared to the calculated density at ambient pressure and temperature $\left.\left(\rho / \rho_{0}\right)\right)$, the agreement with absolute property measurements using traditional experimental approaches (for example, the absolute value calculated for $\rho_{0}$ compared to the experimentally determined value of $\rho_{0}$ ) can remain suboptimal. This adds uncertainty to interpretations of core property observations based solely on molecular dynamics simulations (see Sect. 3 of this article).

In this section, the main experimental high-pressure equipment currently used to study the chemical and physical properties of Earth materials at high pressure and high temperature is briefly reviewed. Readers interested in the history of high-pressure science are referred to Hazen (1999). This review will focus on static compression techniques and will not discuss dynamic compression or in silico techniques. Dynamic compression experimental as well as analytical techniques are reviewed in McMahon (2020).

Crustal and upper mantle pressures between $\sim 0.5$ and $\sim 5 \mathrm{GPa}$ (with most setups capable of a maximum of $\sim 3 \mathrm{GPa}$ ) at temperatures of up to approximately $1873 \mathrm{~K}$ can be reached with a single-stage piston cylinder press (Boyd and England 1960). In these presses, a cylindrical assembly, typically $10-25 \mathrm{~mm}$ in diameter, is used (an example is given in Fig. 6a). The sample is chemically isolated from its exterior through the use of an unreactive capsule (e.g., noble metal), which is surrounded by high-temperature ceramic materials, a cylindrical graphite heater, and insulating materials, which, depending on the temperatures required, can consist of cylinders of $\mathrm{NaCl}$, barium carbonate, or talc combined with silica glass or pyrex (e.g., McDade et al. 2002). The assembly is inserted into the center of a pressure plate consisting of an inner high-strength tungsten carbide (WC) core and an outer softer steel shell. The sample is then compressed by a WC piston and heated through resistive heating of the graphite furnace. Typical sample volumes are on the order of $5-60 \mathrm{~mm}^{3}$.

Piston cylinder presses are not suitable for in situ experimentation because the samples are completely surrounded by metal parts preventing access of light or X-rays. Some indirect measurements of physical properties of Earth materials are nevertheless possible. For example, the so-called falling sphere technique can be used to determine the density of silicate magma relative to the density of minerals at high pressures and high temperatures. This can be achieved by loading spherical mineral grains at the top and bottom of a powdered glass sample, and checking after a piston cylinder experiment whether the mineral grains have sunk, floated, or remained in their original positions (pointing to neutral 
(a)
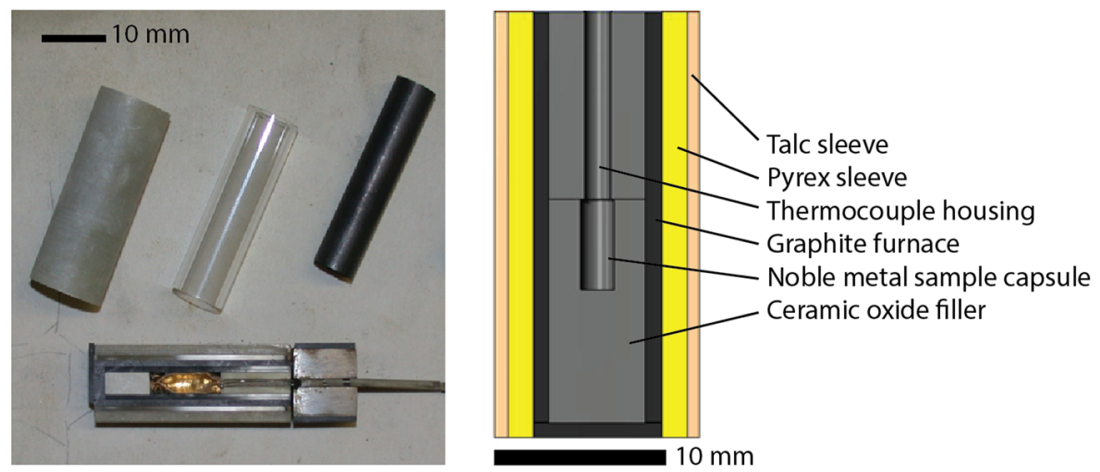

(b)
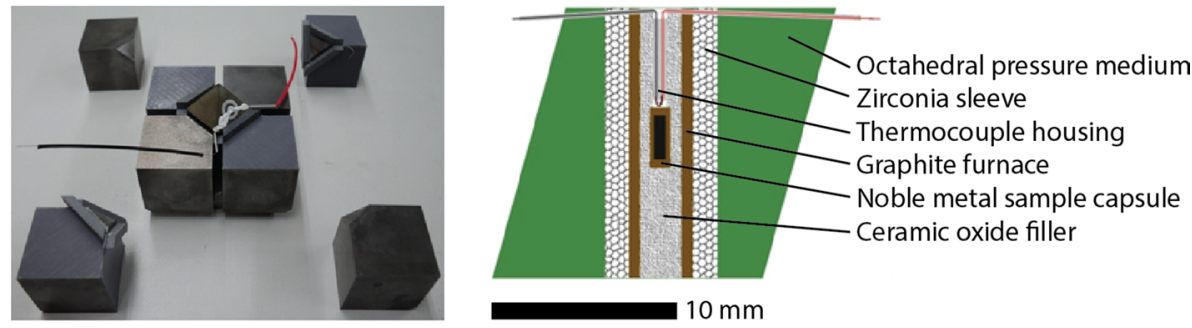

(c)

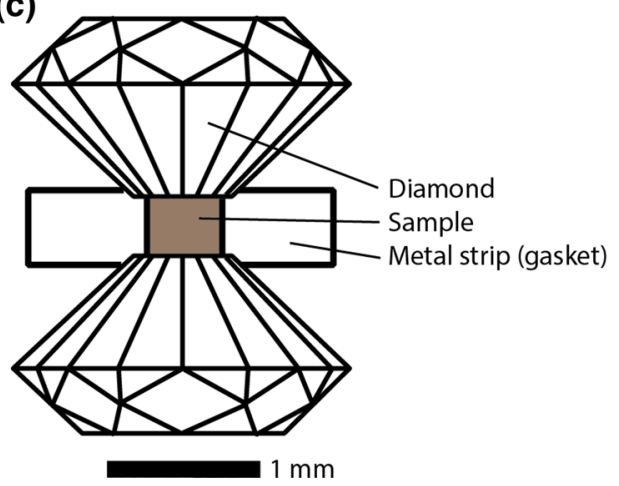

Fig. 6 Examples of static high-pressure experimental setups. a Talc-pyrex piston cylinder assembly (as described in Van Kan Parker et al. 2011b), with sample parts on the left and cross-section drawing on the right b Typical octahedral multi-anvil assembly, with picture of a set of eight second-stage tungsten carbide cubes containing an octahedral pressure medium on the left, and a cross-section drawing on the right (from Knibbe et al. 2018) c Diamond anvil cell cross section

buoyancy). Using equations of state of minerals these experiments can be used to constrain the density of magma in piston cylinder press experiments (e.g., Agee 1998; Van Kan Parker et al. 2011a).

Upper mantle and transition zone pressures (from $\sim 3$ to approximately $23 \mathrm{GPa}$, equivalent to $660 \mathrm{~km}$ depth) can be achieved in so-called Large Volume Presses (LVP), often using a two-stage multi-anvil technique (e.g., Kawai and Endo 1970; Walker et al. 1990). 
Although a range of different multi-anvil presses have been designed and built, most highpressure assemblies used in these apparati are octahedral in shape (e.g., Fig. 6b), with dimensions depending on the desired sample pressure. In the most common type of multianvil, the Kawai-type or 6-8 type, the octahedra are compressed via the corners of eight cube-shaped second-stage anvils that are traditionally made from tungsten carbide. The corners of the cubes that touch the sides of the octahedra are truncated, with smaller truncations enabling higher sample pressures. The set of eight second-stage cubes is backed by six first-stage steel anvils. Samples can be subjected to high pressure when a hydraulic ram progressively decreases the distance between the second-stage anvils by moving the fiststage anvils. Using resistive heating of graphite (at low pressure), lanthanum chromite or rhenium (at high pressure), stable sample temperatures exceeding $2500 \mathrm{~K}$ can be achieved. Sample volumes in these LVP devices are on the order of $1 \mathrm{~mm}^{3}$ (with some very large presses able to process significantly larger volumes particularly suitable for high-quality sample synthesis), sufficient for studies of the partitioning of major and minor elements between silicate minerals and silicate melts in the mantle (important, for example, for magma ocean solidification studies); of the phase relations and evolving mineral compositions in various bulk compositions thought to be present in Earth's mantle, of the partitioning of elements between silicate melt and metal melt (key to models of initial core-mantle segregation in the Earth and subsequent core-mantle chemical interaction); and of diffusion rates in minerals and magmas at high pressure (Ito and Takahashi 1989).

The open space between the eight second-stage anvils, combined with the possibility of widening gaps between the outer anvils by adjusting their shapes, makes it possible for multi-anvil apparatus to be used for in situ experiments. Phase transitions in Earth's upper mantle and transition zone, the mineralogy of the top of Earth's lower mantle, and key physical properties such as mineral densities, P- and S-wave propagation velocities, deep magma viscosities, and reaction rates can be studied in situ with a multi-anvil.

Lower mantle studies are becoming increasingly feasible with multi-anvil devices. With the classic Kawai-type 6-8 design and WC second-stage anvils, maximum pressures were close to $26 \mathrm{GPa}$ due to the limitations of the strength of the WC cubes in combination with the uniaxial nature of the overall compression in the press. This meant only the very top of the lower mantle could be studied with this equipment. In recent years, by increasing the freedom with which the first-stage anvils can move and rotate during compression, or by replacing a hydraulic ram to move the first-stage anvils by an oil bath pressing onto the outside of the first-stage anvils directly (Ito and Takahashi 1989; Stewart et al. 2007) stresses in WC cubes have been limited, and pressures between 27 and over $40 \mathrm{GPa}$ have been achieved (e.g., Ishii et al. 2016). In addition, tungsten carbide cubes can be replaced by sintered diamond cubes, enabling in situ property measurements at pressures of $>100$ GPa in multi-anvil devices (e.g., Yamazaki et al. 2014).

Although these developments indicate that multi-anvil techniques are starting to approach the pressure-temperature field of direct relevant to Earth's core-mantle boundary region and core, most experimental studies aiming to obtain in particular physical property measurements of materials in these deepest regions in the Earth require the use of diamond anvil cells (DACs). With the DAC technique, developed in parallel by two groups in the 1950s (Jamieson et al. 1959; Weir et al. 1959) very small samples (with diameters on the $10 \mathrm{~s}$ to $100 \mathrm{~s}$ micrometer scale) are compressed between the opposed tips of two singlecrystal diamonds (see Fig. 6c). The DAC can be used at pressures overlapping with those of the piston cylinder and multi-anvil apparati discussed above, but can also be used to achieve pressures exceeding those in the center of the Earth. Resistive heating is used in some DAC applications that mostly focus on relatively low-temperature applications, but 


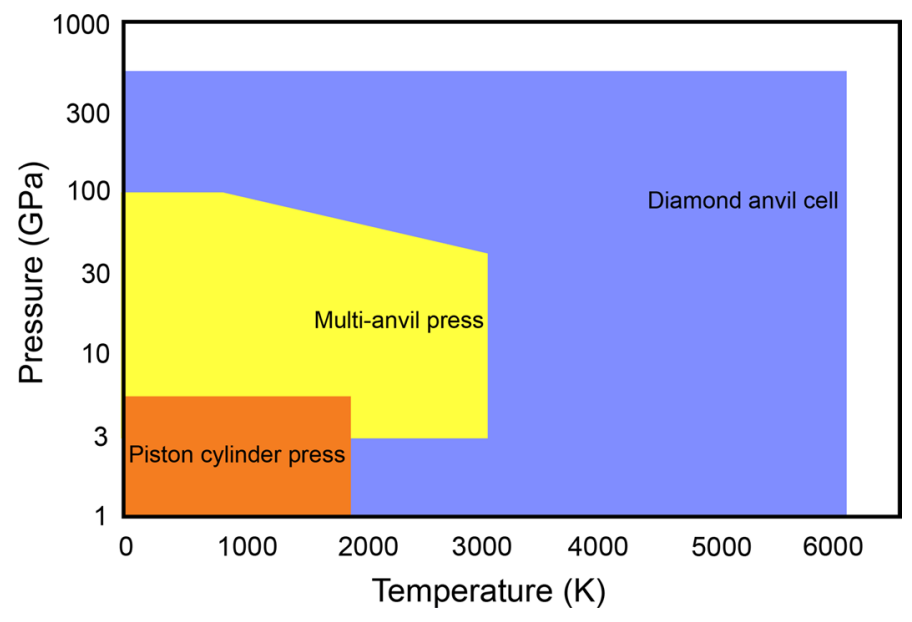

Fig. 7 Compilation of current approximate pressure-temperature capabilities of static high-pressure, hightemperature experimental equipment

in the most cases DAC is combined with laser-heating (achieved by sending laser beams through one or both diamonds and achieving high temperatures by the laser light coupling to the sample material). Sample temperatures cannot be measured by thermocouples anymore, and instead the radiative spectrum of light emitted by the sample is used to constrain temperatures (e.g., Mao and Hemley 1998; Mao et al. 2018).

The DAC setup provides unique access to the samples while they experience highpressure, high-temperature conditions due to the transparency of the diamonds, enabling a wide range of in situ techniques to be applied (McMahon 2020). Although most measurements in a DAC consider physical properties, technical developments including improved capabilities to provide a stable and flat temperature profile across a large part of a sample increasingly enable studies of chemical properties such as melting behavior at lower mantle conditions (e.g., Tateno et al. 2010; Andrault et al. 2018) or in the core (e.g., Miozzi et al. 2020). Figure 7 summarizes the approximate current capabilities of the static high-pressure devices described above in comparison with conditions in the Earth. One final note to make is that the precision of temperature measurements at the conditions of the deep Earth is improving, but that increasing the accuracy of extreme temperature measurements remains very challenging. As a result, error bars on temperature measurements in diamond anvil cell experiments can easily be several 100 degrees. In term, this complicates pressure estimates, particularly at high temperature, because thermal pressure is difficult to quantify if the temperature itself is uncertain. As a result, pressure uncertainties at extreme temperatures can be on the order of 10 percent, which is large compared to the uncertainties in some of the observations that experiments try to explain.

\section{Magnetic Field Observations Providing Information on the Core}

Earth's magnetic field is generated in the liquid outer core. Changing flow patterns of the molten metal present in the outer core provide the variability of the geomagnetic field, both at very long (million to billion year) time scales and at short time scales (e.g., Olsen and 
Mandea 2008). The theory of liquid convection in fast rotating planetary spherical shells is behind these variations, as also discussed in Le Bars et al. (2021). For a fluid shell with a positive temperature gradient imposed between inner and outer core boundary, convection starts as columns outside the tangent cylinder (i.e., Inner Core Boundary, ICB) parallel to the Earth rotation axis (see Fig. 1 in Duka et al. 2015). Motion in form of a vortex around the axis of the column produces cyclonic and anticyclonic columns rotating in the same and in the opposite direction, respectively (Busse 1975). Secondary flows are directed away from the equatorial plane in anticyclonic columns, and in cyclonic columns toward the equatorial plane.

It is not possible to measure the geomagnetic field directly at outer core depths, so understanding better how these processes work is only possible through magnetic measurements at surface or satellite heights. The inversion of the three-component observations (X-North, Y-East, Z-toward Center) of the geomagnetic field is usually performed in spherical harmonic analysis of the potential field in terms of Gauss coefficients and then, taking advantage of the Laplacian properties of the field, can be projected downward to the top of the outer core, supposing an insulating mantle without magnetic sources. Although the latter hypothesis is not perfect, it works for inferring most of the static and dynamic properties of the core (e.g., Backus et al. 1996). This approach gives rise to the so-called geomagnetic field models or reconstructions. Another way to address the problem is using numerical modeling of core dynamics based on the magneto-hydrodynamical equations for convection and magnetic field generation by taking advantage of the information contained in these geomagnetic field models and new approaches based on the data assimilation techniques (for a review about geodynamo modeling see Wicht and Sanchez 2019).

At the Earth's surface, the dipole component of the geomagnetic field accounts for more than $90 \%$ of the entire geomagnetic field. From the first direct measurements of the geomagnetic field intensity in 1840, a decrease of around $9 \%$ of the dipole moment of the Earth's magnetic field has been observed. This decay accelerated from 1990 (Thébault et al. 2015) and seems to coincide with the presence of one of the most intriguing features of the present-day geomagnetic field, i.e., the South Atlantic Anomaly (SAA). This anomaly covers part of South America, the southern Atlantic Ocean and Africa and is related to lower values of the surface intensity than expected in the area. From 1840, it is observed that the SAA areal extent is continuously growing with periods of accelerations and decelerations (Pavón-Carrasco and De Santis 2016).
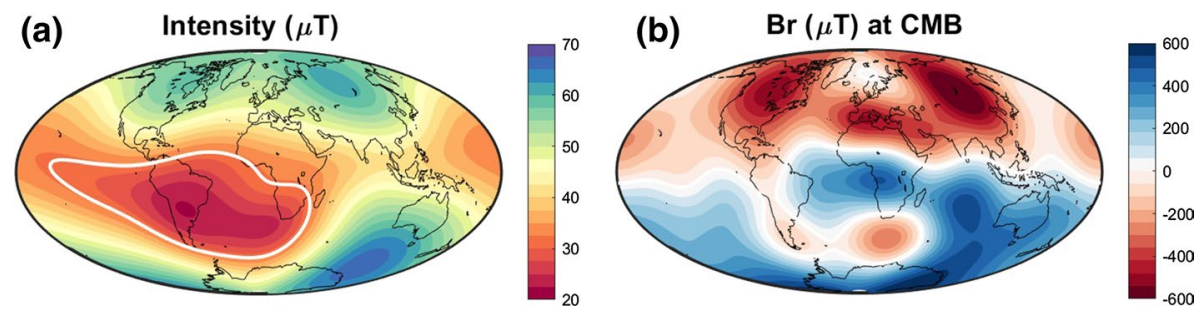

Fig. 8 Geomagnetic field on January 1, 2020. a Intensity at the surface and b radial component (Br) of the geomagnetic field at the CMB on January 1, 2020, from CHAOS-7.2 model (Finlay et al. 2020). The white line in a marks the contour line of 32,000 nT to highlight the area of the SAA defined following De Santis et al. (2012). In b the two RFPs related to the presence of the SAA at the surface are observed in red colors in the Southern Hemisphere. CHAOS-7.2 model is used until degree 13 to calculate the intensity at the surface and until degree six for $\mathrm{Br}$ at the CMB. From Campuzano et al. (2021) 
The SAA is linked with the presence of reversed flux patches (RFPs) at the CMB (e.g., Terra-Nova et al. 2017) (see Fig. 8). It has been observed that these patches are located beneath South Africa and South America and in the last years, the South African RFP has been increasing (e.g., Pavón-Carrasco and De Santis 2016). This situation has been recently reflected at the surface with a split in two different cells of the SAA, one of them over South America and a new one located in the South Atlantic Ocean very close to South Africa (https://www.esa.int/Applications/Observing_the_Earth/Swarm/Swarm_probes_ weakening_of_Earth_s_magnetic_field).

The current decay of the dipole moment and the presence of the SAA related to RFPs at the CMB has motivated some authors to think about a possible upcoming geomagnetic transition, such as an excursion or a reversal (De Santis et al. 2013; Laj and Kissel 2015; Pavón-Carrasco and De Santis 2016). Considering the geomagnetic field as a critical system following De Santis et al. (2013) and De Santis and Qamili (2015), one can estimate a critical time when a possible transition would occur by modeling the recent behavior in time of SAA with a log-periodic singular function. If this behavior is maintained in time, this will provide a critical time of non-return point for a transition around 2030-2060 AD. However, the uncertainty is large, and more data are needed (at least one or two decades more) to better validate this model. It is worth noting that the present dipole moment is too high in comparison to values associated with geomagnetic transitions recorded in rocks (see, e.g., Pavón-Carrasco et al. 2014). On the other hand, the current rate of decay is comparable with that observed during previous reversals (Laj and Kissel 2015). Another way to approach the study of reversals is to use numerical models to better understand the physical processes involved in polarity transitions. One of the first attempts with a numerical geodynamo model was carried out by Glatzmaier and Roberts (1995), but simpler approaches can be also explored. An example of this could be found in the work of Duka et al. (2015). These authors considered a "domino" model to study geomagnetic field reversals. This simplified model consists of a ring of interacting magnetic macrospins placed close to the ICB. Duka et al. (2015) found a good agreement between the secular variation of the dipolar geomagnetic field in previously published models and those given by the "domino" model as well as good approximations to a long series with polarity reversals. The work also predicts a reversal about 75,000 years from now, but it is important to note that this cannot be considered as the exact prediction of a reversal, rather as a probable behavior of the dipolar geomagnetic field in the near future.

Another peculiar feature of the current geomagnetic field is the rapid movement of the magnetic pole with respect to the geographic North Pole, moving from the Canadian Arctic toward Siberia, reaching a present-day velocity of 50-60 km per year (Livermore et al. 2020). Magnetic poles are defined as the points where the inclination of the geomagnetic field is equal to $\pm 90^{\circ}$. The recent acceleration of the magnetic pole observed over the last decades can be explained by the balance between two large lobes of negative flux at the CMB (i.e., Normal Flux Patches, NFPs), here in particular under the regions of Canada and Siberia.

Intriguing relations have also been found between the geomagnetic field and climate in the past at different temporal and spatial scales (e.g., Gallet et al. 2005; Courtillot et al. 2007; Usoskin et al. 2008). A recent work regarding this topic is linked with the evolution of the SAA over the last 300 years (Campuzano et al. 2018). In this case, the connection is established with transfer entropy, a tool used in nonlinear dynamic studies (Schreiber 2000). This parameter is able to provide information about the existence of a link between two time-series and the direction in which this link is produced. The results provided by Campuzano et al. (2018) are based on a previous study that observed a long-term relation 
between the SAA areal extent and Global Sea Level (GSL) rise for the last three centuries (De Santis et al. 2012). The transfer entropy provided with about $90 \%$ of confidence that the short-term (year timescale) link between these two variables exists and goes from SAA (representing geomagnetic field system) to GSL (climate system). This work is interesting because it could help in the determination of a successful physical mechanism able to explain this connection. One of the hypotheses could be an internal mechanism by which a convective dynamism in the outer core could cause a variation of the magnetic field and an elastic deformation at the Earth's surface (Greff-Lefftz et al. 2004).

A recent finding regarding the SAA evolution is the possible relation between the occurrence of geomagnetic jerks and the SAA areal extent (Campuzano et al. 2021). Geomagnetic jerks are abrupt and sharp changes in the secular variation of the geomagnetic field (see Fig. 9a) especially well observed in the East component of the geomagnetic field recorded in magnetic observatories. It seems that jerks occurring during the last two decades happen very close to the minima of the SAA areal extent acceleration (see Fig. 9b).

(a)

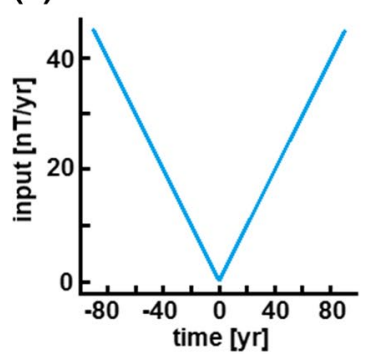

Secular acceleration

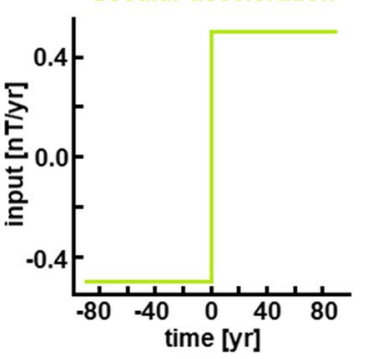

3rd derivative

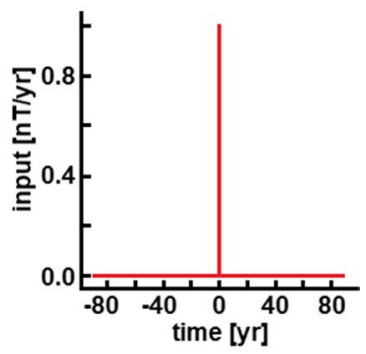

(b)

SAA - jerks link

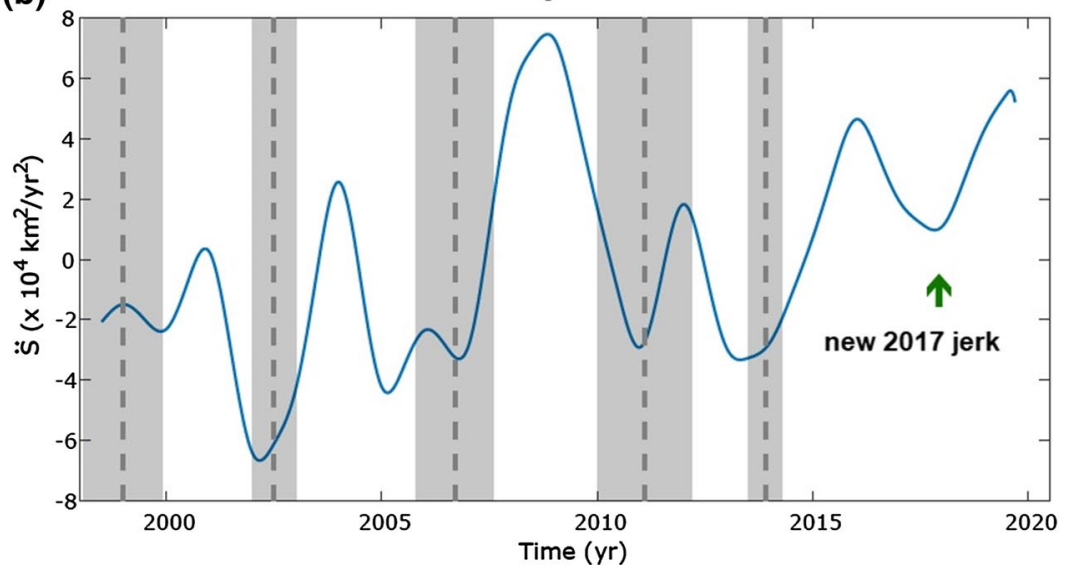

Fig. 9 a Schematic representation of secular variation for a hypothetical component of the magnetic field. The first graph shows the typical V-shape of jerks in the secular variation and the second and third show the secular acceleration and the third differences, respectively. b Second derivative $S$ (i.e., acceleration) of the areal extent of the SAA for the last two decades calculated from CHAOS-7.2 model monthly from January 1998 to March 2020. In dashed vertical gray lines, the mean occurrence times of the well-defined geomagnetic jerks for the last two decades are marked. Shaded bands mark the uncertainty of the occurrence times given by one standard deviation. The green arrow indicates the presence of a new jerk in 2017. From Pinheiro and Travassos (2010) and Campuzano et al. (2021) 
This implies some kind of mechanism that could relate both phenomena and its internal origin. In 2019, Kloss and Finlay (2019) provided evidence for the possible interior origin of the geomagnetic jerks and later Aubert and Finlay (2019) used a magneto-hydrodynamics model and showed that jerks could be produced by the arrival of localized Alfven wave packets radiated from sudden buoyancy releases inside the core. These waves would reach the core surface and focus their energy toward the equatorial plane and along lines of strong magnetic field, creating sharp inter-annual changes in the core flow.

Another intriguing characteristic of the present geomagnetic field is its chaotic and turbulent dynamics. These features cannot be seen directly but is found in the analyses of geomagnetic observatory time-series (Barraclough and De Santis 1997; De Santis et al. 2003). De Santis and Barraclough (1997), from the decay of the geomagnetic field spatial power spectrum as shown by global models of the last 400 years, speculated that the CMB geomagnetic potential profile is fractal with a fractal dimension 1.2, as evidence of a turbulent but organized outer core, as further supported by the inter-relation between temporal and spatial power spectra of the geomagnetic field (De Santis et al. 2003).

The layering structure discussed in Sect. 3.2, in particular the existence of a stratified layer at the top of the core, is also important for the core flow and thus for the magnetic field. The core flow can change completely when such a layer exists in the core (e.g., Gastine et al. 2020). A stable layer underneath the CMB can have crucial dynamical impacts as it inhibits the convective motions in the core. Gastine et al. (2020) found that it primarily acts as a low-pass filter on the magnetic field, smoothing out the rapidly varying and smallscale features by skin effect. Interpenetration of the flow underneath the stratified layer depends on the size of the convective eddies. By studying the periods of the MAC waves, which arise from the interplay between magnetic, Archimedes and Coriolis forces, Buffett (2014) showed that they could correspond to the dominant period of about 60 years of the fluctuations in the observations of the geomagnetic field. This model requires a $140 \mathrm{~km}$ thick stratified layer with a buoyancy frequency comparable to the Earth's rotation rate at the top of the core.

From this brief overview, it is clear that studying key features and short-term and longterm variations in the geomagnetic field can help better understand the processes taking place in the core.

What developments can we expect in future? Will it be possible to predict ahead of time an impending geomagnetic jerk? What about the timing of an eventual future geomagnetic transition or link with climate change? Taking advantage of the properties of the geomagnetic field being chaotic and ergodic (De Santis et al. 2011), one can show that (1) it can be characterized by a mean exponential time scaleafter which it is no longer predictable and (2) it is possible to work in the time domain (this is simpler than the more difficult phase space analyses). Addressing the second question and considering that the capability to predict the geomagnetic field decreases during geomagnetic jerks, Qamili et al. (2013) proposed a method to detect these events, confirming the most well-known jerks and suggesting others.

However, the definitive answer to these questions is not clear. Maybe the clues for the future will be in (1) the acquisition of more magnetic data coming from both the past (remanent magnetization of sedimentary rocks or archeological artifacts and lava flows) and the present (satellites, magnetic observatories at ground) and (2) the implementation of new powerful techniques such as machine learning or artificial intelligence. 


\section{Conclusions and Future Directions}

In this paper, we have tried to give an overview of the situation concerning the deep interior, mainly related to the core and core-mantle-boundary or near. There are many questions that are still open in that field. For instance, the presence of ULVZ and LLSVPs are not questioned but their origin is still under debate. They can have large influences of what is going on at the CMB and vice versa, what is going on at the CMB can influence them. This is certainly a matter of future direction of research.

The processes that take place at the CMB are still unknown, while some observations and some laboratory experiments may constrain them. Constraining how core material may infiltrate into the mantle, if it does, what reactions take place down there, what phases may be produced, and whether models of bulk addition or equilibrium exchange are more realistic are some of the present questions of high importance.

Another interesting matter for future research is the existence of a stratified layer at the top of the core as it would strongly influence thermal, chemical and momentum exchange across the core-mantle boundary and thus have important implications for the dynamics and evolution of the core.

Integration of experimental data, compositional data, and seismic data with geophysical studies such as those described in this volume are the way to go forward.

Generally, the link between geophysical observations (Earth rotation, variation of geomagnetic field) and core-mantle interaction or core processes is also a matter of future direction of research and we only briefly discussed this matter in order to set the basis for the discussions in the other papers of this volume. We have reviewed various methods of detecting density and velocity anomalies as well as topography at the CMB and observations of the geomagnetic field including the geomagnetic jerks. These will also be further addressed in other papers here.

Acknowledgments R.G. Trønnes wrote some of the original text but decided to refrain from co-authorship. We would like to thank him for his contribution. V. Dehant has received funding from the European Research Council (ERC) under the European Union's Horizon 2020 research and innovation program (GRACEFUL Synergy Grant Agreement No. 855677). W. van Westrenen acknowledges funding through a Netherlands Science Organization (N.W.O.) Vici grant. S. A. Campuzano acknowledges the Juan de la Cierva Formación Program (FJC2018-037643-I). A. De Santis acknowledges funding from Pianeta Dinamico-Working Earth project. All the authors would like to thank ISSI for organizing the "Probing the Earth's Deep Interior Using in Synergy Observations of the Earth's Gravity and Magnetic Fields, and of the Earth's Rotation" meeting in these challenging times. Last but not least, the authors want to deeply thank S-I. Karato and an anonymous reviewer for helpful comments.

Open Access This article is licensed under a Creative Commons Attribution 4.0 International License, which permits use, sharing, adaptation, distribution and reproduction in any medium or format, as long as you give appropriate credit to the original author(s) and the source, provide a link to the Creative Commons licence, and indicate if changes were made. The images or other third party material in this article are included in the article's Creative Commons licence, unless indicated otherwise in a credit line to the material. If material is not included in the article's Creative Commons licence and your intended use is not permitted by statutory regulation or exceeds the permitted use, you will need to obtain permission directly from the copyright holder. To view a copy of this licence, visit http://creativecommons.org/licenses/by/4.0/.

\section{References}

Agee CB (1998) Crystal-liquid density inversions in terrestrial and lunar magmas. Phys Earth Planet Inter 107(1-3):63-74. https://doi.org/10.1016/S0031-9201(97)00124-6 
Andrault DG, Bouhifd MA, Bolfan-Casanova N, Hénot JM, Mezouar M (2014) Melting of subducted basalt at the core-mantle boundary. Science 344(6186):892-895. https://doi.org/10.1126/science.1250466

Andrault D, Pesce G, Manthilake G, Monteux J, Bolfan-Casanova N, Chantel J, Novella D, Guignot N, King A, Itié JP, Hennet L (2018) Deep and persistent melt layer in the Archaean mantle. Nat Geosci. https://doi.org/10.1038/s41561-017-0053-9

Anzellini S, Dewaele A, Mezouar M, Loubeyre P, Morard G (2013) Melting of iron at Earth's inner core boundary based on fast X-ray diffraction. Science 340:464-466

Aubert J, Finlay CC (2019) Geomagnetic jerks and rapid hydromagnetic waves focusing at Earth's core surface. Nat Geosci 12:393-398. https://doi.org/10.1038/s41561-019-0355-1

Backus G, Parker R, Constable C (1996) Foundations of Geomagnetism. Cambridge Univ Press, Cambridge

Badro J, Côté AS, Brodholt JP (2014) A seismologically consistent compositional model of Earth's core. Proc Natl Acad Sci 111(21):7542-7545. https://doi.org/10.1073/pnas.1316708111

Badro J, Brodholt JP, Piet H, Siebert J, Ryerson FJ (2015) Core formation and core composition from coupled geochemical and geophysical constraints. Proc Natl Acad Sci 112(40):12310-12314. https://doi. org/10.1073/pnas.1505672112

Badro J, Siebert J, Nimmo F (2016) An early geodynamo driven by exsolution of mantle components from Earth's core. Nature 536:326-328

Ballmer MD, Houser C, Hernlund J, Wentzcovitch RM, Hirose K (2017) Persistence of strong silicaenriched domains in the Earth's lower mantle. Nat Geosci 10:236-240. https://doi.org/10.1038/ngeo2 898

Baron MA, Lord OT, Myhill R, Thomson AR, Wang W, Trønnes RG, Walter MJ (2017) Experimental constraints on melting temperatures in the $\mathrm{MgO}-\mathrm{SiO}_{2}$ system at lower mantle pressures. Earth Planet Sci Lett 472:186-196. https://doi.org/10.1016/j.epsl.2017.05.020

Barraclough DR, De Santis A (1997) Some possible evidence for a chaotic geomagnetic field from observational data. Phys Earth Plan Inter 99:207-220

Becker TW, Boschi L (2002) A comparison of tomographic and geodynamic mantle models. Geochem Geophys Geosyst 3:1003. https://doi.org/10.1029/2001GC000168

Belonoshko AB, Lukinov T, Fu J, Zhao J, Davis S, Simak SI (2017) Stabilization of body-centred cubic iron under inner-core conditions. Nat Geosci 10:312-316

Boschi L, Dziewonski A (1999) High and low resolution images of the earth's mantle-implications of different approaches to tomographic modeling. J Geophys Res 104:567-594

Boschi L, Weemstra C, Verbeke J, Ekstrom G, Zunino A, Giardini D (2013) On measuring surface-wave phase velocity from station-station cross-correlation of ambient signal. Geophys J Int 192:346-358

Boyd FR, England JL (1960) Apparatus for phase-equilibrium measurements at pressures up to 50 kilobars and temperatures up to $1750{ }^{\circ} \mathrm{C}$. J Geophys Res 65:741-748

Brandon AD, Walker RJ (2005) The debate over core-mantle interaction. Earth Planet Sci Lett 232(34):211-225. https://doi.org/10.1016/j.eps1.2005.01.034

Brodholt J, Badro J (2017) Composition of the low seismic velocity E' layer at the top of Earth's core. Geophys Res Lett 44(16):8303-8310. https://doi.org/10.1002/2017GL074261

Buffett BA (2010) Chemical stratification at the top of Earth's core: constraints from observations of nutations. Earth Planet Sci Lett 296(3-4):367-372. https://doi.org/10.1016/j.eps1.2010.05.020

Buffett BA (2014) Geomagnetic fluctuations reveal stable stratification at the top of the Earth's core. Nature 507:484-487

Buffett BA, Seagle CT (2010) Stratification at the top of the core due to chemical interaction with the mantle. J Geophys Res 115:B04407

Burdick S, Lekić V (2017) Velocity variations and uncertainty from transdimensional P-wave tomography of North America. Geophys J Int 209(2):1337-1351. https://doi.org/10.1093/gji/ggx091

Burke K, Torsvik TH (2004) Derivation of Large Igneous Provinces of the past 200 million years from longterm heterogeneities in the deep mantle. Earth Planet Sci Lett 227(3-4):531-538. https://doi.org/10. 1016/j.eps1.2004.09.015

Burke K, Torsvik TH (2012) Derivation of Large Igneous Provinces of the past 200 million years from longterm heterogeneities in the deep mantle. Earth Planet Sci Lett 227(3-4):531-538. https://doi.org/10. 1016/j.eps1.2004.09.015

Busse FH (1975) Patterns of convection in spherical shells. J Fluid Mech 72:67-85. https://doi.org/10.1017/ S0022112075002947

Campuzano SA, De Santis A, Pavón-Carrasco FJ, Osete ML, Qamili E (2018) New perspectives in the study of the Earth's magnetic field and climate connection: the use of transfer entropy. PLoS ONE 13(11):Id. e0207270. https://doi.org/10.1371/journal.pone.0207270 
Campuzano SA, Pavón-Carrasco FJ, De Santis A, González-López A, Qamili E (2021) South Atlantic Anomaly areal extent as a possible indicator of geomagnetic jerks in the satellite era. Front Earth Sci 8:563. https://doi.org/10.3389/feart.2020.607049

Caracas R, Hirose K, Nomura R, Ballmer MD (2019) Melt-crystal density crossover in a deep magma ocean. Earth Planet Sci Lett 516:202-211

Chen J (2016) Lower-mantle materials under pressure. Science 351(6269):122-123. https://doi.org/10.1126/ science.aad7813

Clesi V, Bouhifd MA, Bolfan-Casanova N, Manthilake G, Schiavi F, Raepsaet C, Bureau H, Khodja H, Andrault D (2018) Low hydrogen contents in the cores of terrestrial planets. Sci Adv 4(3):Id. e1701876. https://doi.org/10.1126/sciadv.1701876

Colombi A, Nissen-Meyer T, Boschi L, Giardini D (2014) Seismic waveform inversion for core-mantle boundary topography. Geophys J Int 198:55-71

Conrad CP, Steinberger B, Torsvik TH (2013) Stability of active mantle upwelling revealed by net characteristics of plate tectonics. Nature 498(7455):479-482. https://doi.org/10.1038/nature12203

Cottaar S, Romanowicz B (2012) An unsually large ULVZ at the base of the mantle near Hawaii. Earth Planet Sci Lett 355:213-222. https://doi.org/10.1016/j.eps1.2012.09.005

Courtillot V, Gallet Y, Le Mouël J-L, Fluteau F, Genevey A (2007) Are there connections between the Earth's magnetic field and climate? Earth Planet Sci Lett 253(3-4):328-339

de Koker N, Steinle-Neumann G, Vlcek V (2012) Electrical resistivity and thermal conductivity of liquid Fe alloys at high P and T, and heat flux in Earth's core. Proc Natl Acad Sci USA 109:4070-4073

de Koker N, Karki BB, Stixrude L (2013) Thermodynamics of the $\mathrm{MgO}-\mathrm{SiO}_{2}$ liquid system in Earth's lowermost mantle from first principles. Earth Planet Sci Lett 361:58-63. https://doi.org/10.1016/j.eps1. 2012.11.026

De Santis A, Barraclough DR (1997) A fractal interpretation of the topography of the scalar geomagnetic scalar potential at the core-mantle boundary. Pure Appl Geophys 149(4):747-760

De Santis A, Qamili E (2015) geosystemics: a systemic view of the Earth's Magnetic field and the possibilities for an imminent geomagnetic transition. Pure Appl Geophys 172:75-89. https://doi.org/10.1007/ s00024-014-0912-x

De Santis A, Barraclough DR, Tozzi R (2003) Spectral and temporal spectra of the geomagnetic field and their scaling properties. Phys Earth Planet Int 135:125-134

De Santis A, Qamili E, Cianchini G (2011) Ergodicity of the recent geomagnetic field. Phys Earth Plan Int 186:103-110

De Santis A, Qamili E, Spada G, Gasperini P (2012) Geomagnetic South Atlantic Anomaly and global sea level rise: a direct connection? J Atmos Sol-Terr Phys 74:129-135

De Santis A, Qamili E, Wu L (2013) Toward a possible next geomagnetic transition? Nat Hazards Earth Syst Sci 13:3395-3403. https://doi.org/10.5194/nhess-13-3395

Defraigne P, Dehant V, Wahr JM (1996) Internal loading of a homogeneous compressible Earth with phase boundaries. Geophys J Int 125:173-192. https://doi.org/10.1111/j.1365-246X.1996.tb06544.X

Dehant V, Mathews PM (2015) Precession, nutation, and wobble of the Earth. Cambridge University Press, ISBN: 9781107092549

Dehant V, Wahr JM (1991) The response of a compressible, non-homogeneous Earth to internal loading: Theory. J Geomagn Geoelectr 43:157-178. https://doi.org/10.5636/jgg.43.157

Deschamps F, Li Y, Tackley PJ (2015) Large-scale thermo-chemical structure of the deep mantle: observations and models. In: Khan A, Deschamps F (eds) The Earth's heterogeneous mantle. Springer Geophysics. https://doi.org/10.1007/978-3-319-15627-9_15

Deschamps F, Rogister Y, Tackley PJ (2018) Constraints on core-mantle boundary topography from models of thermal and thermochemical convection. Geophys J Int 212(1):164-188

Deuss A, Woodhouse J (2001) Seismic observations of splitting of the mid-transition zone discontinuity in Earth's mantle. Science 294(5541):354-357. https://doi.org/10.1126/science.1063524

Dobson DP, Lindsay-Scott A, Hunt SA, Bailey A, Wood IG, Brodholt JP, Vocadlo L, Wheeler J (2019) Anisotropic diffusion creep in post-perovskite provides a new model for deformation at the core-mantle boundary. Proc Nat Acad Sci 116:26389-26393

Dubrovinsky L, Dubrovinskaia N, Narygina O, Kantor I, Kuznetzov A, Prakapenka VB, Vitos L, Johansson B, Mikhaylushkin AS, Simak SI, Abrikosov IA (2007) Body-centered cubic iron-nickel alloy in Earth's core. Science 316:1880-1883

Duka B, Peqini K, De Santis A, Pavón-Carrasco FJ (2015) Using "domino" model to study the secular variation of the geomagnetic dipolar moment. Phys Earth Planet Inter 242:9-23. https://doi.org/10.1016/j. pepi.2015.03.001

Dziewonski AM, Anderson DL (1981) Preliminary reference Earth model. Phys Earth Planet Inter $25: 297-356$ 
Fei Y, Brosh E (2014) Experimental study and thermodynamic calculations of phase relations in the $\mathrm{Fe}-\mathrm{C}$ system at high pressure. Earth Planet Sci Lett 408:155-162. https://doi.org/10.1016/j.eps1.2014.09. 044

Finlay CC, Kloss C, Olsen N, Hammer M, Toeffner-Clausen L, Grayver A et al (2020) The CHAOS-7 geomagnetic field model and observed changes in the South Atlantic Anomaly. Earth Planets Space 72:66. https://doi.org/10.1186/s40623-020-01252-9

Forte AM (2007) Constraints on seismic models from other disciplines-implications for mantle dynamics and composition. In: Dziewonski A, Romanowicz B (eds) Treatise on geophysics, vol 1. Elsevier, pp $805-858$

Forte AM, Mitrovica J (2001) Deep-mantle high-viscosity flow and thermochemical structure inferred from seismic and geodynamic data. Nature 410(6832):1049-1056

Forte AM, Mitrovica JX, Woodward RL (1995) Seismic-geodynamic determination of the origin of excess ellipticity of the core-mantle boundary. Earth Planet Sci Lett 9(22):1013-1016

Gallet Y, Genevey A, Fluteau F (2005) Does Earth's magnetic field secular variation control centennial climate change? Earth Planet Sci Lett 236:339-347

Garnero EJ, McNamara AK (2008) Structure and Dynamics of Earth's Lower Mantle. Science 320(5876):626. https://doi.org/10.1126/science.1148028

Garnero EJ, Helmberger DV, Grand SP (1993) Constraining outermost core velocity with SmKS waves. Geophys Res Lett 20:2463-2466. https://doi.org/10.1029/93GL02823

Gastine T, Aubert J, Fournier A (2020) Dynamo-based limit to the extent of a stable layer atop Earth's core. Geophys J Int 222(2):1433-1448. https://doi.org/10.1093/gji/ggaa250

Gibbons SJ, Kværna T, Tiira T, Kozlovskaya E (2020) A benchmark case study for seismic event relative location. Geophys J Int 223(2):1313-1326. https://doi.org/10.1093/gji/ggaa362

Gillet N, Jault D, Canet E (2017) Excitation of travelling torsional normal modes in an Earth's core model Geophys. J Int 210:1503-1516. https://doi.org/10.1093/gji/ggx237

Gillet N, Gerick F, Angappan R, Jault D (2021) A dynamical prospective on interannual geomagnetic field changes. Surv Geophys. https://doi.org/10.1007/s10712-021-09664-2

Girard J, Amulele G, Farla R, Mohiuddin A, Karato SI (2016) Shear deformation of bridgmanite and magnesiowüstite aggregates at lower mantle conditions. Science 351(6269):144-147. https://doi. org/10.1126/science.aad3113

Giuliani A, Jackson MG, Fitzpayne A, Dalton H (2021) Remnants of early Earth differentiation in the deepest mantle-derived lavas. Proc Natl Acad Sci 118(1):Id. 2015211118. https://doi.org/10.1073/ pnas. 2015211118

Glane S, Buffett B (2018) Enhanced core-mantle coupling due to stratification at the top of the core. Front Earth Sci 6:id. 171. https://doi.org/10.3389/feart.2018.00171

Glatzmaier GA, Roberts PH (1995) A three-dimensional self-consistent computer simulation of a geomagnetic field reversal. Nature 377:203-209

Glatzmaier GA, Roberts PH (1996) On the magnetic sounding of planetary interiors. Phys Earth Planet Inter 98:207-220

Gomi H, Hirose K (2015) Electrical resistivity and thermal conductivity of hcp Fe-Ni alloys under high pressure: Implications for thermal convection in the Earth's core. Phys Earth Planet Inter 247:2-10

Gomi H, Ohta K, Hirose K, Labrosse S, Caracas R, Verstraete MJ, Hernlund JW (2013) The high conductivity of iron and thermal evolution of the Earth's core. Phys Earth Planet Inter 224:88-103

Green DH, Ringwood AE (1963) Mineral assemblages in a model mantle composition. J Geophys Res 68(3):937-945. https://doi.org/10.1029/JZ068i003p00937

Greenwood RC, Barrat J-A, Miller MF, Anand M, Dauphas N, Franchi IA, Sillard P, Starkey NA (2018) Oxygen isotopic evidence for accretion of Earth's water before a high-energy Moon-forming giant impact. Sci Adv 4:Id. eaao5928

Greff-Lefftz M, Pais MA, Le Mouel J-L (2004) Surface gravitational field and topography changes induced by the Earth's fluid core motions. J Geodesy 78:386-392

Gross RS (2015) Earth rotation variations-long period, in physical geodesy. In: Herring TA (ed) Treatise on geophysics, vol 11, 2nd ed. Elsevier, Amsterdam

Gubbins D, Davies CJ (2013) The stratified layer at the core-mantle boundary caused by barodiffusion of oxygen, sulphur and silicon. Phys Earth Planet Inter 215:21-28. https://doi.org/10.1016/j.pepi. 2012.11.001

Gülcher AJP, Gebhardt DJ, Ballmer MD, Tackley PJ (2020) Variable dynamic styles of primordial heterogeneity preservation in the Earth's lower mantle. Earth Planet Sci Lett 536:Id. 116160. https:// doi.org/10.1016/j.eps1.2020.116160

Gwinn CR, Herring TA, Shapiro II (1986) Geodesy by radio interferometry: studies of the forced nutations of the Earth: 2. Interp J Geophys Res 91(B5):4755-4765 
Hager BH, Richards MA (1989) Long-wavelength variations in Earth's geoid: physical models and dynamical implications. Phil Trans R Soc Lond 328(1599):309-327

Hager BH, Clayton RW, Richards MA, Comer RP, Dziewonski AM (1985) Lower mantle heterogeneity, dynamic topography and the geoid. Nature 313(6003):541-545. https://doi.org/10.1038/313541a0

Hayden LA, Watson EB (2007) A diffusion mechanism for core-mantle interaction. Nature 450(7170):709-711. https://doi.org/10.1038/nature06380

Hayden LA, Watson EB (2008) Grain boundary mobility of carbon in Earth's mantle: a possible carbon flux from the core. Proc Natl Acad Sci 105(25):8537-8541. https://doi.org/10.1073/pnas.07108 06105

Hazen RM (1999) The Diamond makers. Cambridge University Press, New York

Helffrich G, Kaneshima S (2010) Outer-core compositional stratification from observed core wave speed profiles. Nature 468(7325):807-810. https://doi.org/10.1038/nature09636

Helffrich G, Hirose K, Nomura R (2020) Thermodynamical modeling of liquid Fe-Si-Mg-O: molten magnesium silicate release from the core. Geophys Res Lett 47(21):Id. e89218. https://doi.org/10. 1029/2020GL089218

Hernlund JW, Jellinek AM (2010) Dynamics and structure of a stirred partially molten ultralow-velocity zone. Earth Planet Sci Lett 296(1-2):1-8. https://doi.org/10.1016/j.epsl.2010.04.027

Hernlund JW, McNamara AK (2015) The core-mantle boundary region. In: Schubert G (ed) Treatise on geophysics, vol 7.11, 2nd ed. Elsevier, pp 461-519. https://doi.org/10.1016/B978-0-444-53802-4. 00136-6

Herring TA, Buffett BA, Mathews PM, Shapiro II (1991) Forced nutations of an Earth: influence of inner core dynamics 3. Very long interferometry data analysis. J Geophys Res 96(B5):8259-8273

Herzberg C, Vidito C, Starkey NA (2016) Nickel-cobalt contents of olivine record origins of mantle peridotite and related rocks. Am Miner 101(9):1952-1966. https://doi.org/10.2138/am-2016-5538

Hide R (1977) Towards a theory of irregular variations in the length of the day and core-mantle coupling. Philos Trans R Soc Lond Ser A Math Phys Sci 284(1326):547-554. https://doi.org/10.1098/rsta.1977. 0030

Hide R, Horai K (1968) On the topography of the core-mantle interface. Phys Earth Planet Inter 1(5):305-308

Hirose K, Labrosse S, Hernlund JW (2013) Composition and state of the core. Annu Rev Earth Planet Sci 41:657-691. https://doi.org/10.1146/annurev-earth-050212-124007

Hirose K, Morard G, Sinmyo R, Umemoto K, Hernlund J, Helffrich G, Labrosse S (2017) Crystallization of silicon dioxide and compositional evolution of the Earth's core. Nature 543:99-102

Hirose K, Wood B, Vočadlo L (2021) Light elements in the Earth's core. Nat Rev Earth Environ 2:645-658. https://doi.org/10.1038/s43017-021-00203-6

Irifune T, Tsuchiya T (2015) Phase transitions and mineralogy of the lower mantle. In: Schubert G (ed) Treatise of geophysics, volume 2-mineralogy of the Earth, Chapter 2.03, pp 33-60

Irving JCE, Cottaar S, Lekić V (2015) Seismically determined elastic parameters for Earth's outer core. Sci Adv 4(6):Id. eaar2538. https://doi.org/10.1126/sciadv.aar2538

Ishii M, Tromp J (1999) Normal-mode and free-air gravity constraints on lateral variations in velocity and density of Earth's mantle. Science 285(5431):1231-1236. https://doi.org/10.1126/science.285.5431. 1231

Ishii M, Tromp J (2001) Even-degree lateral variations in the mantle constrained by free oscillations and the free-air gravity anomaly. Geophys J Int 1(145):77-96

Ishii T, Shi L, Huang R, Tsujino N, Druzhbin D, Myhill R, Li Y, Wang L, Yamamoto T, Miyajima N, Kawazoe T, Nishiyama N, Higo Y, Tange Y, Katsura T (2016) Generation of pressures over 40 GPa using Kawai-type multi-anvil press with tungsten carbide anvils. Rev Sci Instrum 87:024501. https://doi. org/10.1063/1.4941716

Ito E, Takahashi E (1989) Postspinel transformations in the system $\mathrm{Mg}_{2} \mathrm{SiO}_{4}-\mathrm{Fe}_{2} \mathrm{SiO}_{4}$ and some geophysical implications. J Geophys Res 94(B8):10637-10646. https://doi.org/10.1029/JB094iB08p10637

Jackson I (1983) Some geophysical constraints on the chemical composition of the earth's lower mantle. Earth Planet Sci Lett 62(1):91-103. https://doi.org/10.1016/0012-821X(83)90073-0

Jackson I (1998) Elasticity, composition and temperature of the Earth's lower mantle: a reappraisal. Geophys J Int 134:2091-2311

Jackson MG, Konter JG, Becker TW (2017) Primordial helium entrained by the hottest mantle plumes. Nature 542(7641):340-343. https://doi.org/10.1038/nature21023

Jackson MG, Blichert-Toft J, Halldórsson SA, Mundl-Petermeier A, Bizimis M, Kurz MD, Price AA, Harðardóttir S, Willhite LN, Breddam K, Becker TW, Fischer RA (2020) Ancient helium and tungsten isotopic signatures preserved in mantle domains least modified by crustal recycling. Proc Natl Acad Sci 117(49):30993-31001. https://doi.org/10.1073/pnas.2009663117 
Jackson MG, Becker TW, Steinberger B (2021) Spatial characteristics of recycled and primordial reservoirs in the deep mantle. Geochem Geophys Geosyst 22:Id. e2020GC009525

Jamieson JC, Lawson AW, Nachtrieb ND (1959) New device for obtaining X-ray diffraction patterns from substances exposed to high pressure. Rev Sci Instrum 30(11):1016-1019

Jault D, Le Mouël J (1990) Core-mantle boundary shape: constraints inferred from the pressure torque acting between the core and the mantle. Geophys J Int 101(1):233-241

Kanda RVS, Stevenson DJ (2006) Suction mechanism for iron entrainment into the lower mantle. Geophys Res Lett 33(2):Id. L02310. https://doi.org/10.1029/2005GL025009

Kaneshima S (2018) Array analyses of SmKS waves and the stratification of Earth's outermost core. Phys Earth Planet Inter 276:234-246. https://doi.org/10.1016/j.pepi.2017.03.006

Kaneshima S, Helffrich G (2013) $\mathrm{V}_{\mathrm{P}}$ structure of the outermost core derived from analysing large-scale array data of SmKS waves. Geophys J Int 193(3):1537-1555. https://doi.org/10.1093/gji/ggt042

Kaneshima S, Matsuzawa T (2015) Stratification of Earth's outermost core inferred from SmKS array data. Prog Earth Planet Sci 2:Id. 15:1-15. https://doi.org/10.1186/s40645-015-0046-5

Karato SI (2013) Rheological properties of minerals and rocks. Phys Chem the Deep Earth. https://doi.org/ 10.1002/9781118529492.ch4

Karato SI (2014) Does partial melting explain geophysical anomalies? Phys Earth Planet Int 228:300-306. https://doi.org/10.1016/j.pepi.2013.08.006

Kato C, Umemoto K, Ohta K, Tagawa S, Hirose K, Ohishi Y (2020) Stability of fcc phase FeH to 137 GPa. Am Miner 105(6):917-921. https://doi.org/10.2138/am-2020-7153

Kawai N, Endo S (1970) The generation of ultrahigh hydrostatic pressures by a split sphere apparatus. Rev Sci Instrum 41:1178-1181

Kennett B, Engdahl ER, Buland R (1995) Constraints on seismic velocities in the Earth from travel times. Geophys J Int 122:108-124

Kim T, Ko B, Greenberg E, Prakapenka V, Shim S.-H, Lee Y (2020) Low melting temperature of anhydrous mantle materials at the core-mantle boundary. Geophys Res Lett 47:e2020GL089345

Kloss C, Finlay CC (2019) Time-dependent low-latitude core flow and geomagnetic field acceleration pulses. Geophys J Int 217(1):140-168. https://doi.org/10.1093/gji/ggy545

Knibbe JS, Luginbuehl SM, Stoevelaar R, van der Plas W, van Harlingen DM, Rai N, Steenstra ES, van der Geer R, van Westrenen W (2018) Calibration of a multi-anvil high-pressure apparatus to simulate planetary interior conditions. EPJ Techn Instrum. https://doi.org/10.1140/epjti/s40485-018-0047-z

Koelemeijer P, Ritsema J, Deuss A, van Heijst HJ (2016) SP12RTS: a degree-12 model of shear- and compressional wave velocity for Earth's mantle. Geophys J Int 204(2):1024-1039

Koelemeijer P, Deuss A, Ritsema J (2017) Density structure of Earth's lowermost mantle from Stoneley mode splitting observations. Nat Commun 8(1):Id. 15241

Koelemeijer P, Schuberth BSA, Davies DR, Deuss A, Ritsema J (2018) Constraints on the presence of postperovskite in Earth's lowermost mantle from tomographic-geodynamic model comparisons. Earth Planet Sci Lett 494:226-238. https://doi.org/10.1016/j.eps1.2018.04.056

Komabayashi T (2021) Phase relations of Earth's core-forming materials. Crystals 11(6):581. https://doi. org/10.3390/cryst11060581

Krasnoshchekov D, Ovtchinnikov V, Polishchuk V (2019) Dissimilarity of the Earth's inner core surface under South America and Northeastern Asia revealed by core reflected phases. J Geophys Res Solid Earth. https://doi.org/10.1029/2019JB017408

Labrosse S, Hernlund JW, Coltice N (2007) A crystallizing dense magma ocean at the base of the Earth's mantle. Nature 450(7171):866-869. https://doi.org/10.1038/nature06355

Laj C, Kissel C (2015) An impending geomagnetic transition? Hints from the past. Front Earth Sci 3:61. https://doi.org/10.3389/feart.2015.00061

Laneuville M, Hernlund J, Labrosse S, Guttenberg N (2018) Crystallization of a compositionally stratified basal magma ocean. Phys Earth Planet Inter 276:86-92. https://doi.org/10.1016/j.pepi.2017.07.007

Lassak T, McNamara A, Garnero E, Zhong S (2010) Core-mantle boundary topography as a possible constraint on lower mantle chemistry and dynamics. Earth Planet Sci Lett 289:232-241

Lau HCP, Mitrovica JX, Davis JL, Tromp J, Yang HY, Al-Attar D (2017) Tidal tomography constrains Earth's deep-mantle buoyancy. Nature 551(7680):321-326. https://doi.org/10.1038/nature24452

Lay T (2015) The surge of great earthquakes from 2004 to 2014. Earth Planet Sci Lett 409:133-146. https:// doi.org/10.1016/j.epsl.2014.10.047

Lay T, Young CJ (1990) The stably-stratified outermost core revisited. Geophys Res Lett 17(11):2001-2004. https://doi.org/10.1029/GL017i011p02001

Le Bars M, Barik A, Burmann F, Lathrop DP, Noir J, Schaeffer N, Triana SA (2021) Fluid dynamics experiments for planetary interiors. Surv Geophys. https://doi.org/10.1007/s10712-021-09681-1 
Leveque J-J, Rivera L, Wittlinger G (1993) On the use of the checker-board test to assess the resolution of tomographic inversions. Geophys J Int 115(1):313-318

Li X-D, Giardini D, Woodhouses JH (1991) Large-scale three-dimensional even-degree structure of the Earth from splitting of long-period normal modes. J Geophys Res Solid Earth 96(B1):551-577

Li Y, Vočadlo L, Sun T, Brodholt JP (2020) The Earth's core as a reservoir of water. Nat Geosci 13(6):453458. https://doi.org/10.1038/s41561-020-0578-1

Liebske C, Frost DJ (2012) Melting phase relations in the $\mathrm{MgO}-\mathrm{MgSiO}_{3}$ system between 16 and $26 \mathrm{GPa}:$ implications for melting in Earth's deep interior. Earth Planet Sci Lett 345:159-170. https://doi.org/ 10.1016/j.eps1.2012.06.038

Liu X, Zhong S (2015) Constraining mantle viscosity structure for a thermochemical mantle using the geoid observation. Geophys Geochem Geosys 17(3):895-913

Liu J, Li J, Hrubiak R, Smith JS (2016) Origins of ultralow velocity zones through slab-derived metallic melt. Proc Natl Acad Sci USA 113:5547-5551

Livermore PW, Finlay CC, Bayliff M (2020) Recent north magnetic pole acceleration towards Siberia caused by flux lobe elongation. Nat Geosci 13:387-391

Lock SJ, Stewart ST, Petaev MI, Leinhardt Z, Mace MT, Jacobsen SB, Ćuk M (2018) The origin of the Moon within a terrestrial synestia. J Geophys Re Planets 123:910-951. https://doi.org/10.1002/2017J E005333

Malavergne V, Siebert J, Guyot F, Gautron L, Combes R, Hammouda T, Borensztajn S, Frost D, Martinez I (2004) Si in the core? New high-pressure and high-temperature experimental data. Geochim Cosmochim Acta 68(20):4201-4211. https://doi.org/10.1016/j.gca.2004.04.013

Malavergne V, Bureau H, Raepsaet C, Gaillard F, Poncet M, Surblé S, Sifré D, Shcheka S, Fourdin C, Deldicque D, Khodja H (2019) Experimental constraints on the fate of $\mathrm{H}$ and $\mathrm{C}$ during planetary coremantle differentiation. Implic Earth Icarus 321:473-485. https://doi.org/10.1016/j.icarus.2018.11.027

Man C, Huang M (2011) A simple explicit formula for the voigt-reuss-hill average of elastic polycrystals with arbitrary crystal and texture symmetries. J Elast 105:29-48. https://doi.org/10.1007/ s10659-011-9312-y

Mandea M, Narteau C, Panet I, Le Mouël JL (2015) Gravimetric and magnetic anomalies produced by dissolution-crystallization at the core-mantle boundary. J Geophys Res Solid Earth 120(9):59836000. https://doi.org/10.1002/2015JB012048

Manga M (1996a) Mixing of heterogeneities in the mantle: effect of viscosity differences. Geophys Res Lett 23:403-406

Manga M (1996b) Dynamics of drops in cavity flows: aggregation of high viscosity ratio drops. J Fluid Mech 8:1732-1737

Mao HK, Hemley RJ (1998) New windows on the Earth's deep interior. In: Hemley RJ (ed) Ultrahighpressure mineralogy: physics and chemistry of the Earth's deep interior, vol 37. Mineralogical Society of America, Reviews in mineralogy, Washington, DC, pp 1-32

Mao HK, Chen XJ, Ding Y, Li B, Wang L (2018) Solids, liquids, and gases under high pressure. Rev Mod Phys 90:1500-7

Mashino I, Miozzi F, Hirose K, Morard G, Sinmyo R (2019) Melting experiments on the Fe-C binary system up to $255 \mathrm{GPa}$ : Constraints on the carbon content in the Earth's core. Earth Planet Sci Lett 515:135-144. https://doi.org/10.1016/j.eps1.2019.03.020

Mashino I, Murakami M, Miyajima N, Petitgirard S (2020) Experimental evidence for silica-enriched Earth's lower mantle with ferrous iron dominant Bridgmanite. Proc Natl Acad Sci 117(45):2789927905. https://doi.org/10.1073/pnas.1917096117

Mathews PM, Buffett BA, Herring TA, Shapiro II (1991a) Forced nutations of the Earth: influence of inner core dynamics. I Theory J Geophys Res 96(B5):8219-8242

Mathews PM, Buffett BA, Herring TA, Shapiro II (1991b) Forced nutations of the Earth: Influence of inner core dynamics. II. Numerical results and comparisons. J Geophys Res 96(B5):8243-8258

Mathews PM, Herring TA, Buffett BA (2002) Modeling of nutation and precession: new nutation series for non-rigid Earth and insights into the Earth's interior. J Geophys Res 107(B4):ETG 3-1-ETG 3-26. https://doi.org/10.1029/2001JB000390

McDade P, Wood BJ, van Westrenen W, Brooker R, Gudmundsson G, Soulard H, Najorka J, Blundy J (2002) Pressure corrections for a selection of piston-cylinder cell assemblies. Mineral Mag 66:1021-1028

McDonough WF, Sun SS (1995) The composition of the Earth. Chem Geol 120(3-4):223-253. https:// doi.org/10.1016/0009-2541(94)00140-4

McMahon MI (2020) Synchrotron and FEL studies of matter at high pressures. In: Jaeschke E, Khan S, Schneider J, Hastings J (eds) Synchrotron light sources and free-electron lasers. Springer. https:// doi.org/10.1007/978-3-030-23201-6_67 
McNamara AK (2019) A review of large low shear velocity provinces and ultra low velocity zones. Tectonophysics 760:199-220. https://doi.org/10.1016/j.tecto.2018.04.015

Miozzi F, Morard G, Antonangeli D, Baron MA, Boccato S, Pakhomova A, Garbarino G, Mezouar M, Fiquet $\mathrm{G}$ (2020) Eutectic melting of $\mathrm{Fe}-3$ at\% $\mathrm{Si}-4$ at\% $\mathrm{C}$ up to $200 \mathrm{GPa}$ and implications for the Earth's core. Earth Planet Sci Lett. https://doi.org/10.1016/j.eps1.2020.116382

Morelli A, Dziewonski AM (1987) Topography of the core-mantle boundary and lateral homogeneity of the liquid core. Nature 325:678-683

Mundl A, Touboul M, Jackson MG, Day JMD, Kurz MD, Lekic V, Helz RT, Walker RJ (2017) Tungsten-182 heterogeneity in modern ocean island basalts. Science 356(6333):66-69. https://doi.org/ 10.1126/science.aal4179

Mundl-Petermeier A, Walker RJ, Jackson MG, Blichert-Toft J, Kurz MD, Halldórsson SA (2019) Temporal evolution of primordial tungsten-182 and ${ }^{3} \mathrm{He} /{ }^{4} \mathrm{He}$ signatures in the Iceland mantle plume. Chem Geol 525:245-259. https://doi.org/10.1016/j.chemgeo.2019.07.026

Mundl-Petermeier A, Walker RJ, Fischer RA, Lekic V, Jackson MG, Kurz MD (2020) Anomalous ${ }^{182}$ W in high ${ }^{3} \mathrm{He} /{ }^{4} \mathrm{He}$ ocean island basalts: fingerprints of Earth's core? Geochim Cosmochim Acta 271:194-211. https://doi.org/10.1016/j.gca.2019.12.020

Murakami M, Ohishi Y, Hirao N et al (2012) A perovskitic lower mantle inferred from high-pressure, high-temperature sound velocity data. Nature 485:90-94. https://doi.org/10.1038/nature11004

Nakada M, Karato SI (2012) Low viscosity of the bottom of the Earth's mantle inferred from the analysis of Chandler wobble and tidal deformation. Phys Earth Planet Inter 192:68-80. https://doi.org/ 10.1016/j.pepi.2011.10.001

Nimmo F (2015) Thermal and compositional evolution of the core. In: Schubert G (ed) Treatise on geophysics, vol 9.08, 2nd ed. Elsevier, pp 201-219

Nomura R, Hirose K, Uesugi K, Ohishi Y, Tsuchiyama A, Miyake A, Ueno Y (2014) Low core-mantle boundary temperature inferred from the solidus of pyrolite. Science 343:522-525

Ohta K, Kuwayama Y, Hirose K, Shimizu K, Ohishi Y (2016) Experimental determination of the electrical resistivity of iron at Earth's core conditions. Nature 534:95-98

Olsen N, Mandea M (2008) Rapidly changing flows in the Earth's core. Nature Geosciences 1(6):390-394. https://doi.org/10.1038/ngeo203

Otsuka K, Karato S (2012) Deep penetration of molten iron into the mantle caused by a morphological instability. Nat Lett 492:243-246. https://doi.org/10.1038/nature11663

Ozawa K, Anzai M, Hirose K, Sinmyo R, Tateno S (2018) Experimental determination of eutectic liquid compositions in the $\mathrm{MgO}-\mathrm{SiO}_{2}$ system to the lowermost mantle pressures. Geophys Res Lett 45(18):9552-9558. https://doi.org/10.1029/2018GL079313

Pavón-Carrasco FJ, De Santis A (2016) The South Atlantic Anomaly: the key for a possible geomagnetic reversal. Front Earth Sci 4:40. https://doi.org/10.3389/feart.2016.00040

Pavón-Carrasco FJ, Osete ML, Torta JM, De Santis A (2014) A geomagnetic field model for the Holocene based on archaeomagnetic and lava flow data. Earth Planet Sci Lett 388:98-109. https://doi.org/10. 1016/j.eps1.2013.11.046

Pinheiro KJ, Travassos JM (2010) Impulses of the geomagnetic secular variation (Jerks) at vassouras magnetic observatory detected by wavelet analysis. Revista Brasileira De Geofísica 28(1):37-46

Poirier JP (1994) Light elements in the Earth's core: a critical review. Phys Earth Planet Inter 85:319-337

Porcelli D, Elliott T (2008) The evolution of He Isotopes in the convecting mantle and the preservation of high ${ }^{3} \mathrm{He} /{ }^{4} \mathrm{He}$ ratios. Earth Planet Sci Lett 269:175-185

Porcelli D, Halliday AN (2001) The core as a possible source of mantle helium. Earth Planet Sci Lett 192(1):45-56. https://doi.org/10.1016/S0012-821X(01)00418-6

Pozzo M, Davies C, Gubbins D, Alfe D (2012) Thermal and electrical conductivity of iron at Earth's core conditions. Nature 485:355-358

Pradhan GK, Fiquet G, Siebert J, Auzende AL, Morard G, Antonangeli D, Garbarino G (2015) Melting of MORB at core-mantle boundary. Earth Planet Sci Lett 431:247-255. https://doi.org/10.1016/j.epsl. 2015.09.034

Qamili E, De Santis A, Isac A, Mandea M, Duka B, Simonyan A (2013) Geomagnetic jerks as chaotic fluctuations of the Earth's magnetic field. Geochem Geophys Geosyst 14(4):839-850

Rekier J, Trinh A, Triana SA, Dehant V (2019) Inertial modes in near-spherical geometries. Geophys J Int 216(2):777-793. https://doi.org/10.1093/gji/ggy465

Rekier J, Triana SA, Trinh A, Dehant V (2020) Inertial modes of a freely rotating ellipsoidal planet and their relation to nutations. Planet Sci J 1(1):Id. 20. https://doi.org/10.3847/PSJ/ab93c8

Rekier J, Chao BF, Chen J, Dehant V, Rosat S, Zhu P (2021) Earth's rotation: observations and relation to deep interior. Surv Geophys. https://doi.org/10.1007/s10712-021-09669-x 
Ringwood AE (1962a) A model for the upper mantle. J Geophys Res 67(2):857-867. https://doi.org/10. 1029/JZ067i002p00857

Ringwood AE (1962b) Mineralogical constitution of the deep mantle. J Geophys Res 67(10):4005-4010. https://doi.org/10.1029/JZ067i010p04005

Rizo H, Andrault D, Bennett NR, Humayun M, Brandon A, Vlastelic I, Moine B, Poirier A, Bouhifd MA, Murphy DT (2019) 182W evidence for core-mantle interaction in the source of mantle plumes. Geochem Perspect Lett 11:6-11. https://doi.org/10.7185/geochemlet.1917

Romanowicz B (2003) Global mantle tomography: progress status in the past 10 years. Annu Rev Earth Planet Sci 31(31):303-328. https://doi.org/10.1146/annurev.earth.31.091602.113555

@@ @aikia A, Frost DJ, Rubie DC (2008) Splitting of the 520-kilometer seismic discontinuity and chemical heterogeneity in the mantle. Science 319(5869):1515. https://doi.org/10.1126/science.1152818

Sasao T, Okubo S, Saito M (1980) A simple theory on the dynamical effects of a stratified fluid core upon nutational motion of the Earth. In: Nutation and the Earth's rotation, proceedings of the symposium, Kiev, Ukrainian SSR, May 23-28, 1977. D. Reidel Publishing Co., Dordrecht, pp 165-183

Schreiber T (2000) Measuring information transfer. Phys Rev Lett 85(2):461-464. https://doi.org/10.1103/ PhysRevLett.85.461

Simmons NA, Forte AM, Grand SP (2009) Joint seismic, geodynamic and mineral physical constraints on three-dimensional mantle heterogeneity: Implications for the relative importance of thermal versus compositional heterogeneity. Geophys J Int 177(5):1284-1304

Simmons NA, Forte AM, Boschi L, Grand SP (2010) GyPSuM: a joint tomographic model of mantle density and seismic wave speeds. J Geophys Res 115(B12):CiteID B12310. https://doi.org/10.1029/2010J B007631

Sinmyo R, Hirose K, Ohishi Y (2019) Melting curve of iron to $290 \mathrm{GPa}$ determined in a resistance-heated diamond-anvil cell. Earth Planet Sci Lett 510:45-52

Soldati G, Boschi L, Piersanti A (2003) Outer core density heterogeneity and the discrepancy between PKP and PcP travel time observations. Geophys Res Lett. https://doi.org/10.1029/2002GL016647

Soldati G, Boschi L, Forte A (2012) Tomography of core-mantle boundary and lowermost mantle coupled by geodynamics. Geophys J Int 189:730-746

Soldati G, Koelemeijer P, Boschi L, Deuss A (2013) Constraints on core-mantle boundary topography from normal mode splitting. Geochem Geophys Geosyst 14(5):1333-1342

Souriau A (2007) Deep Earth structure-the Earth's cores. In: G. Schubert (ed) Treatise on Geophysics, Vol. 1: seismology and the structure of the Earth, ed. , Publ. Elsevier Amsterdam, pp. 655-693 (2007).

Sreenivasan B, Gubbins D (2008) Dynamos with weakly convecting outer layers: implications for core-mantle boundary interaction. Geophys Astrophys Fluid Dyn 102(4):395-407. https://doi.org/10.1080/03091 920801900047

Stacey F, Loper D (2007) A revised estimate of the conductivity of iron alloy at high pressure and implications for the core energy balance. Phys Earth Planet Inter 161:13-18

Steinberger B, Holme R (2008) Mantle flow models with core-mantle boundary constraints and chemical heterogeneities in the lowermost mantle. J Geophys Res 113(B5):Id. B05403. https://doi.org/10.1029/2007J B005080

Steinberger B, Torsvik TH (2008) Absolute plate motions and true polar wander in the absence of hotspot tracks. Nature 452(7187):620-623. https://doi.org/10.1038/nature06824

Steinberger B, Torsvik TH (2010) Toward an explanation for the present and past locations of the poles. Geochem Geophys Geosyst 11(6):Id. Q06W06. https://doi.org/10.1029/2009GC002889

Stewart AJ, Schmidt MW, van Westrenen W, Liebske C (2007) Mars: a new core-crystallization regime. Science 316(5829):1323. https://doi.org/10.1126/science.1140549

Stixrude L (2012) Structure of iron to 1 Gbar and 40000 K. Phys Rev Lett 108:Id. 055505

Stixrude L, Lithgow-Bertelloni C (2011) Thermodynamics of mantle minerals-II. Phase Equilib Geophys J 184(3):1180-1213. https://doi.org/10.1111/j.1365-246X.2010.04890.x

Stixrude L, Lithgow-Bertelloni C (2012) Geophysics of chemical heterogeneity in the mantle. Annu Rev Earth Planet Sci 40(1):569-595. https://doi.org/10.1146/annurev.earth.36.031207.124244

Stixrude L, de Koker N, Sun N, Mookherjee M, Karki BB (2009) Thermodynamics of silicate liquids in the deep Earth. Earth Planet Sci Lett 278(3-4):226-232. https://doi.org/10.1016/j.epsl.2008.12.006

Tateno S, Hirose K, Ohishi Y, Tatsumi Y (2010) The structure of Iron in Earth's inner core. Science 330(6002):359-361. https://doi.org/10.1126/science.1194662

Tateno S, Hirose K, Ohishi Y (2014) Melting experiments on peridotite to lowermost mantle conditions. J Geophys Res 123:4684-4694

Tateno S, Kuwayama Y, Hirose K, Ohishi Y (2015) The structure of Fe-Si alloy in Earth's inner core. Earth Planet Sci Lett 418:11-19 
Tateno S, Hirose K, Sakata S, Yonemitsu K, Ozawa H, Hirata T, Hirao N, Ohishi Y (2018) Melting phase relations and element partitioning in MORB to lowermost mantle conditions. J Geophys Res Solid Earth 123(7):5515-5531. https://doi.org/10.1029/2018JB015790

Tateno S, Hirose K, Komabayashi T, Ozawa H, Ohishi Y (2021) The structure of Fe-Ni alloy in Earth's inner core. Geophys Res Lett 39(12):Id. L12305. https://doi.org/10.1029/2012GL052103

Terra-Nova F, Amit H, Hartmann GA, Trindade RIF, Pinheiro KJ (2017) Relating the South Atlantic Anomaly and geomagnetic flux patches. Phys Earth Planet Inter 266:39-53

Thébault E, Finlay CC, Beggan CD et al (2015) International geomagnetic reference field: the 12th generation. Earth Planets Space 67:79. https://doi.org/10.1186/s40623-015-0228-9

Thorne MS, Garnero EJ, Grand SP (2004) Geographic correlation between hot spots and deep mantle lateral shear-wave velocity gradients. Phys Earth Planet Inter 146(1-2):47-63. https://doi.org/10.1016/j.pepi. 2003.09.026

Torsvik TH (2019) Earth history: a journey in time and space from base to top. Tectonophysics 760:297-313. https://doi.org/10.1016/j.tecto.2018.09.009

Torsvik TH, Smethurst MA, Burke K, Steinberger B (2006) Large igneous provinces generated from the margins of the large low-velocity provinces in the deep mantle. Geophys J 167(3):1447-1460. https://doi.org/ 10.1111/j.1365-246X.2006.03158.x

Torsvik TH, Burke K, Steinberger B, Webb SJ, Ashwal LD (2010) Diamonds sampled by plumes from the coremantle boundary. Nature 466(7304):352-355. https://doi.org/10.1038/nature09216

Torsvik TH, van der Voo R, Doubrovine PV, Burke K, Steinberger B, Ashwal LD, Trønnes RG, Webb SJ, Bull AL (2014) Deep mantle structure as a reference frame for movements in and on the Earth. Proc Natl Acad Sci 111(24):8735-8740. https://doi.org/10.1073/pnas.1318135111

Torsvik TH, Steinberger B, Ashwal LD, Doubrovine PV, Trønnes RG, Polat A (2016) Earth evolution and dynamics - a tribute to Kevin Burke. Can J Earth Sci 53(11):1073-1087. https://doi.org/10.1139/ cjes-2015-0228

Triana SA, Rekier J, Trinh A, Dehant V (2019) The coupling between inertial and rotational eigenmodes in planets with liquid cores. Geophys J Int 218(2):1071-1086. https://doi.org/10.1093/gji/ggz212

Triana SA, Trinh A, Rekier J, Zhu P, Dehant V (2021) The viscous and ohmic damping of the Earth's free core nutation. J Geophys Res 126:Id. e2020JB021042. https://doi.org/10.1029/2020JB021042

Trønnes RG, Mohn CE, Eigenmann KR (2018) He and Ne diffusion in bridgmanite and lower mantle structure. Goldschmidt Conf Abstr 02d, 0830

Trønnes RG, Baron MA, Eigenmann KR, Guren MG, Heyn BH, Løken A, Mohn CE (2019) Core formation, mantle differentiation and core-mantle interaction within Earth and the terrestrial planets. Tectonophysics 760:165-198. https://doi.org/10.1016/j.tecto.2018.10.021

Tsuno K, Frost DJ, Rubie DC (2013) Simultaneous partitioning of silicon and oxygen into the Earth's core during early Earth differentiation. Geophys Res Lett 40(1):66-71. https://doi.org/10.1029/2012GL054116

Umemoto K, Hirose K (2020) Chemical compositions of the outer core examined by first principles calculations. Earth Planet Sci Lett 531:Id. 116009. https://doi.org/10.1016/j.eps1.2019.116009

Usoskin I, Korte M, Kovaltsov GA (2008) Role of centennial geomagnetic changes in local atmospheric ionization. Geophys Res Lett 35:L05811

van Kan Parker M, Agee CB, Duncan MS, van Westrenen W (2011a) Compressibility of molten Apollo 17 orange glass and implications for density crossovers in the lunar mantle. Geochim Cosmochim Acta 75:1161-1172

van Kan Parker M, Mason PRD, van Westrenen W (2011b) Experimental study of trace element partitioning between lunar orthopyroxene and anhydrous silicate melt: effects of lithium and iron. Chem Geol 285:1-14

Vasco DW, Johnson LR, Marques O (1999) Global Earth structure: inference and assessment. Geophys J Int 137(2):381-407

Vocadlo L (2015) Earth's core: iron and iron alloys. In: Schubert G (ed) Treatise on geophysics, vol 2.06, pp $117-147$

Wade J, Wood BJ (2016) The oxidation state and mass of the Moon-forming impactor. Earth Planet Sci Lett 442:186-193. https://doi.org/10.1016/j.eps1.2016.02.053

Walker D, Carpenter MA, Hitch CM (1990) Some simplifications to multianvil devices for high pressure experiments. Am Miner 75:1020-1028

Walter MJ, Trønnes RG (2004) Early Earth differentiation. Earth Planet Sci Lett 225(3):253-269. https://doi. org/10.1016/j.eps1.2004.07.008

Weir CE, Lippincott ER, Vanvalkenburg A, Bunting EN (1959) Infrared studies in the 1-micron to 15-micron region to 30,000 atmospheres. J Res Natl Bur Stand Sect A Phys Chem 63(1):55-62

Wicht J, Sanchez S (2019) Advances in geodynamo modelling. Geophys Astrophys Fluid Dyn 113(1-2):2-50. https://doi.org/10.1080/03091929.2019.1597074 
Wicks JK, Jackson JM, Sturhahn W (2010) Very low sound velocities in iron-rich (Mg, Fe)O: implications for the core-mantle boundary region. Geophys Res Lett. https://doi.org/10.1029/2010GL043689

Wimert J, Hier-Majumder S (2012) A three-dimensional microgeodynamic model of melt geometry in the Earth's deep interior. J Geophys Res. https://doi.org/10.1029/2011JB009012

Wohlers A, Wood BJ (2017) Uranium, thorium and REE partitioning into sulfide liquids: implications for reduced S-rich bodies. Geochim Cosmochim Acta 205:226-244. https://doi.org/10.1016/j.gca.2017.01. 050

Wolf AS, Jackson JM, Dera P, Prakapenka VB (2015) The thermal equation of state of (Mg, Fe)SiO 3 bridgmanite (perovskite) and implications for lower mantle structures. J Geophys Res Solid Earth 120(11):74607489. https://doi.org/10.1002/2015JB012108

Wong J, Davies CJ, Jones CA (2021) A regime diagram for the slurry F-layer at the base of Earth's outer core. Earth Planet Sci Lett. https://doi.org/10.1016/j.eps1.2021.116791

Wood BJ, Walter MJ, Wade J (2006) Accretion of the Earth and segregation of its core. Nature 441(7095):825833. https://doi.org/10.1038/nature04763

Yamazaki D, Ito E, Yoshino T, Tsujino N, Yoneda A, Guo X, Xu F, Higo Y, Funakoshi K (2014) Over 1 Mbar generation in the Kawai-type multianvil apparatus and its application to compression of $\left(\mathrm{Mg}_{0.92} \mathrm{Fe}_{0.08}\right)$ $\mathrm{SiO}_{3}$ perovskite and stishovite. Phys Earth Planet Inter 228:262-267

Yoshida M (2008) Core-mantle boundary topography estimated from numerical simulations of instantaneous mantle flow. Geophys Geochem Geosys 9(7):Id. Q07002. https://doi.org/10.1029/2008GC002008

Yoshino T, Walter MJ, Tomoo K (2003) Core formation in planetesimals triggered by permeable flow. Nature 422(6928):154-157. https://doi.org/10.1038/nature01459

Yuan K, Romanowicz B (2017) Seismic evidence for partial melting at the root of major hot spot plumes. Science 357(6349):393-397. https://doi.org/10.1126/science.aan0760

Yuan L, Steinle-Neumann G (2020) Strong sequestration of hydrogen into the Earth's core during planetary differentiation. Geophys Res Lett 47:Id. e2020GL088303

Zhu P, Triana SA, Rekier J, Trinh A, Dehant V (2021) Quantification of corrections for the main lunisolar nutation components and analysis of the free core nutation remaining in the nutation residuals. J Geod 95:Id. 57. https://doi.org/10.1007/s00190-021-01513-9

Publisher's Note Springer Nature remains neutral with regard to jurisdictional claims in published maps and institutional affiliations. 